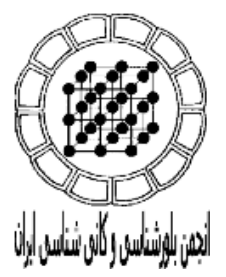

\title{
مقاله يخزوهشى
}

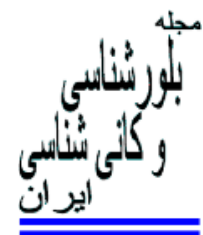

\section{ويزگى هاى تكتونو -ماكمايى كابروهاى قليايى در شمال فتح آباد زرند (شمال غرب كرمان): بر هايهى شيمى كانى ييروكسن مليحه حَلستانى}

كروه زمينشناسى، دانشكله علوم يايه و مهندسى، دانشعاه ولايت، /يرانشهر، /يران

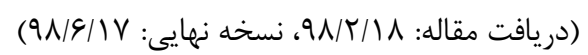

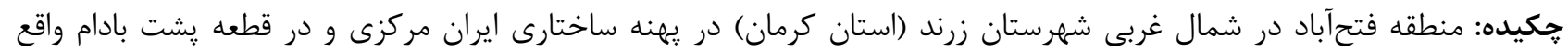

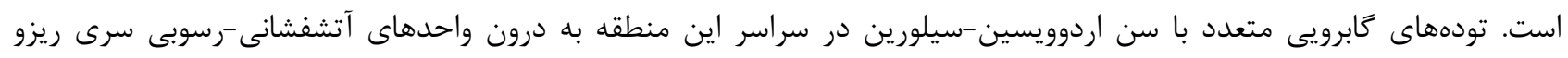

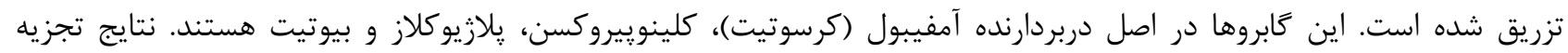

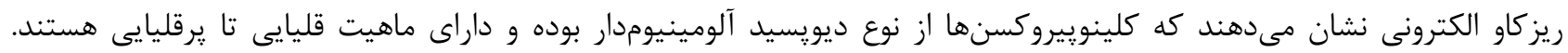

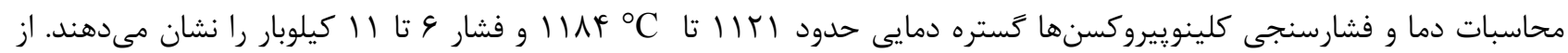

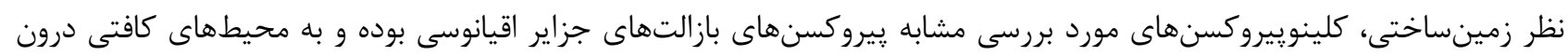

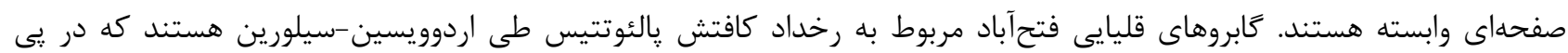

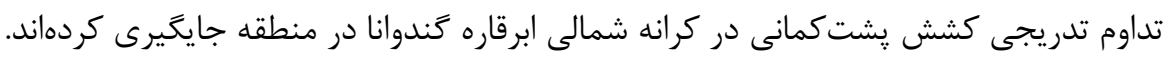

وازههاى كليدى: كابرو؛ قليا يي؛ كلينوييروكسن؛ شيمى كانى؛ فتحآباد؛ قطعه بشت بادام.

كَندوانا جدا شده و سرانجام در زمان يرمين-ترياس به كرانه مقدمه

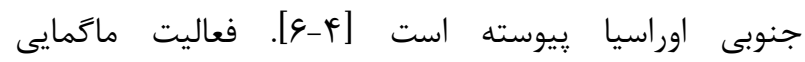
زايش و فرگشت ناوههاي اقيانوسى تتيسى در درازاي تاريخ

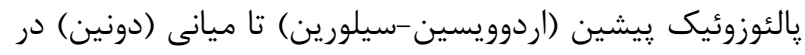

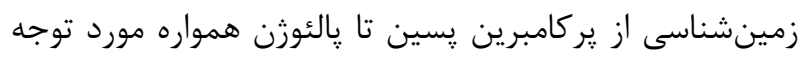

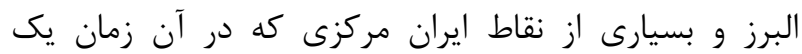

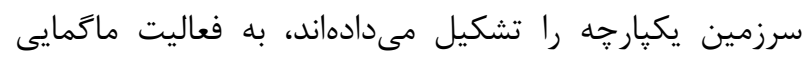

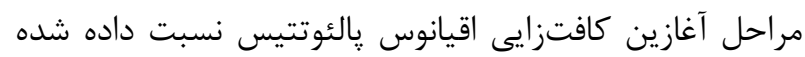

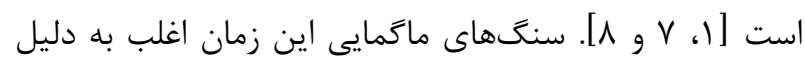
يراكندگى و فرسودىى تاكنون كمتر مورد توجه قرار گرفتهاند.

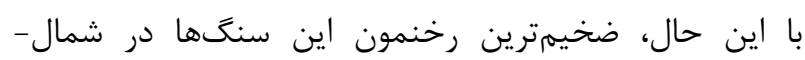

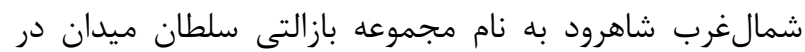

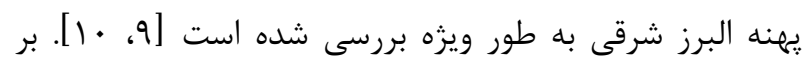

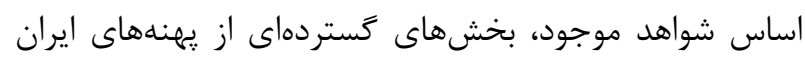

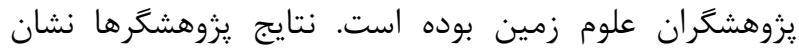

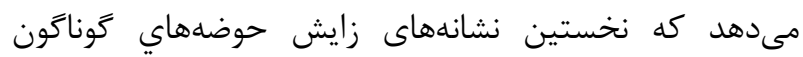
تتيس را كه سبب قطعه قطعه شدن و جدايش ابرقاره كَندوانا

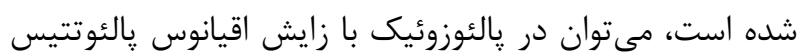

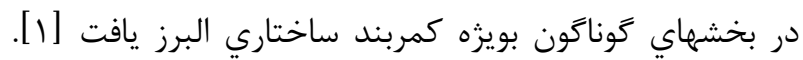

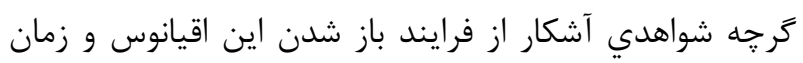

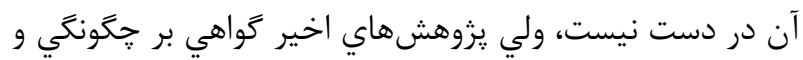

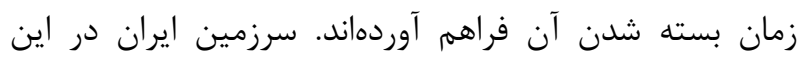

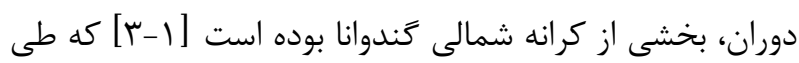

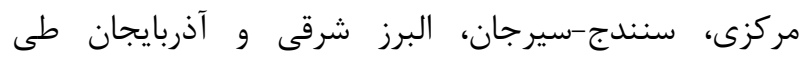

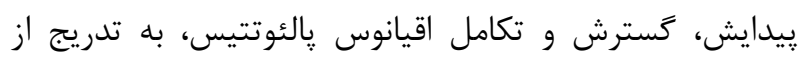




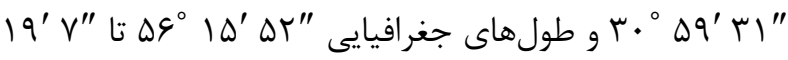
تونه در شمال غربى استان كرمان واقع است. اين منطقه از نظر

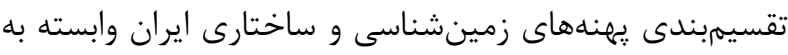

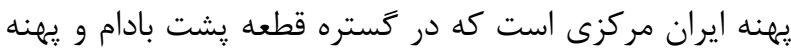
زمينساختى كاشمر-كرمان قرار دارد (شكل إن الف). در اين

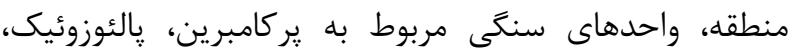
مزوزوئيك و ترشيرى را مىتوان ديده كرد (شكل ا ب). سرى

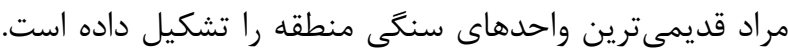

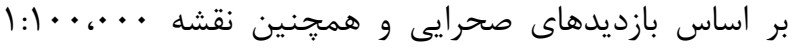

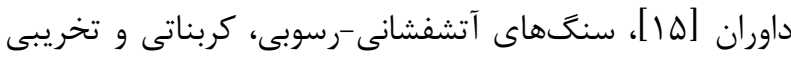

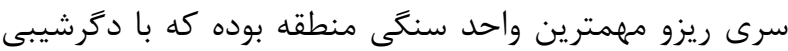

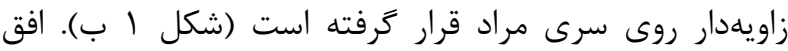

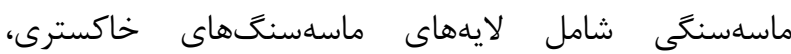
خاكسترى مايل به سبز و صورتى و ميانلايههايى از شيلهاى

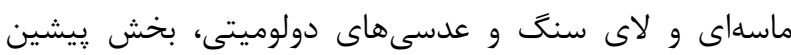

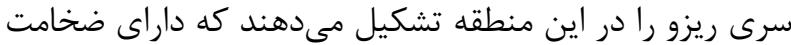

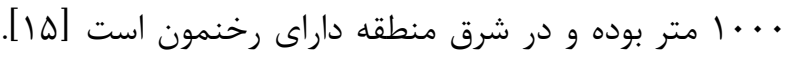
بخشهاى بالايى اين سرى از مجموعه متنوعى از سنگ ستهاى

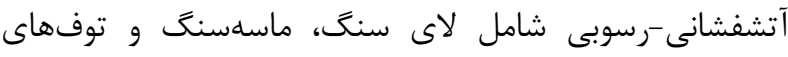

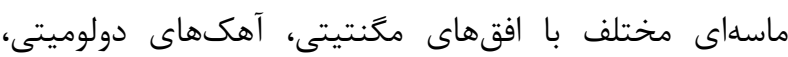
توفهاى با تركيب نيمهاسيدى، توفيت، تودههاى نفوذى و

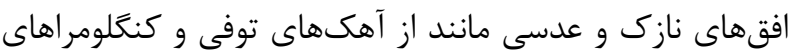

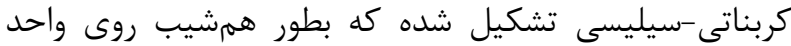

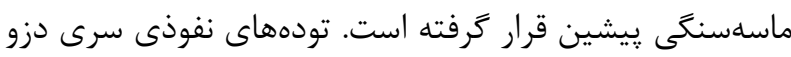

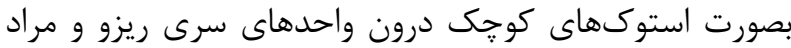

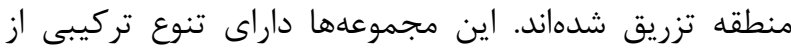

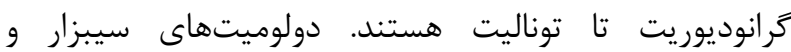
واحدهاى كربناتى جمال توالىهاى سنكى ديكر در اين منطقه

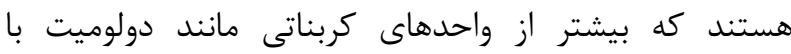

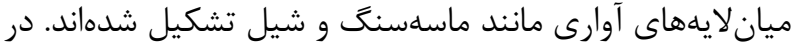

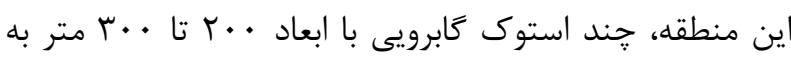

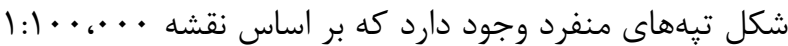

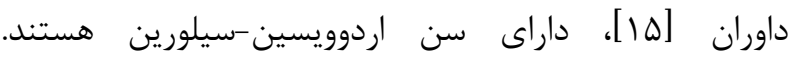
سنگهاى كابرويى به درون واحدهاى آتشفشانى-رسوبى سرى آنى

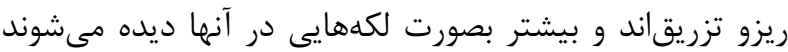

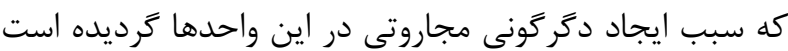

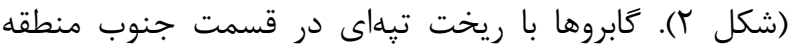
مورد بررسى ديده مىشوند (شكل r ت ت).
קالئوزوئيك ييشين دستخوش اين فعاليت ماگمايى شدهاند و

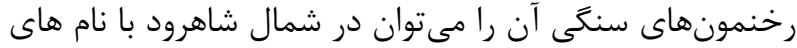

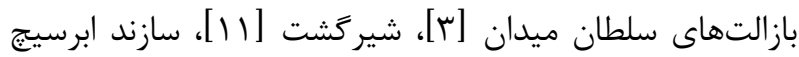

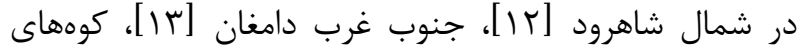

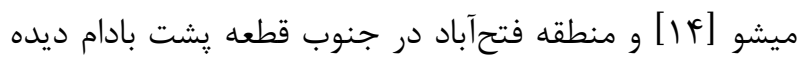

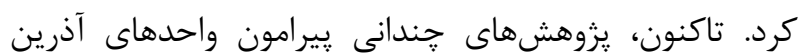

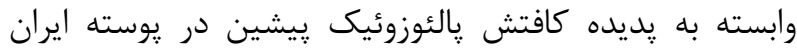

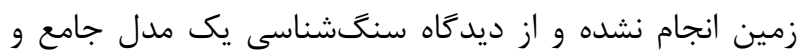

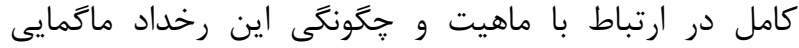

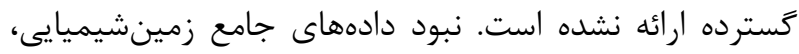

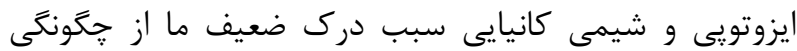

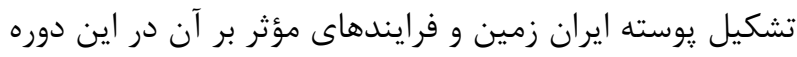

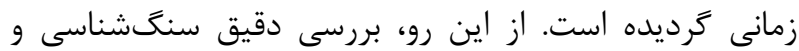

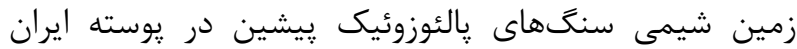

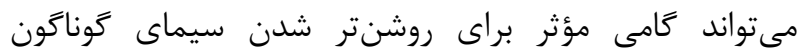

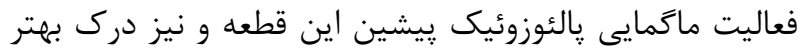

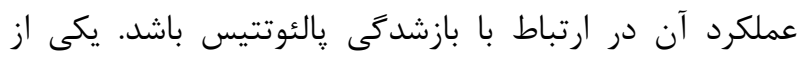

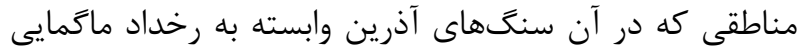

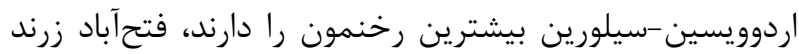
واقع در جنوب قطعه يشت بادام و يهنه فلززايى بافق است. اين

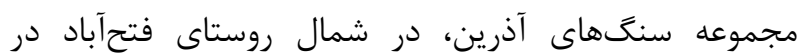

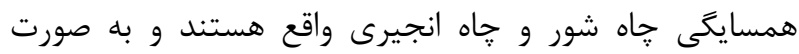
تعداد بسيارى استوكهاى كابرو-ديوريتى و دايكهاى ديابازى

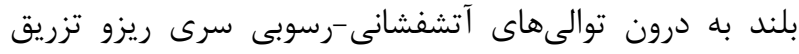

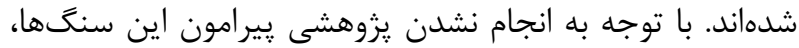

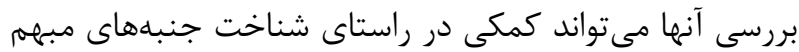

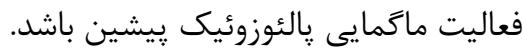
تركيب شيميايى كانىهايى مانند پِيروكسن ابزار كاربردى

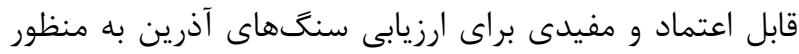

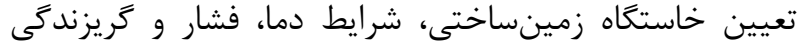

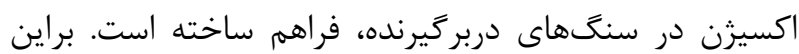

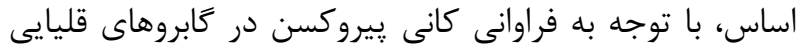

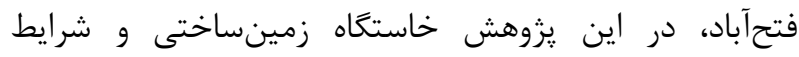

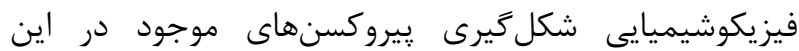
كابروها با استفاده از تركيب شيميايى بيروكسن، بررسى شده

زمينشناسى

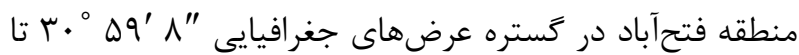




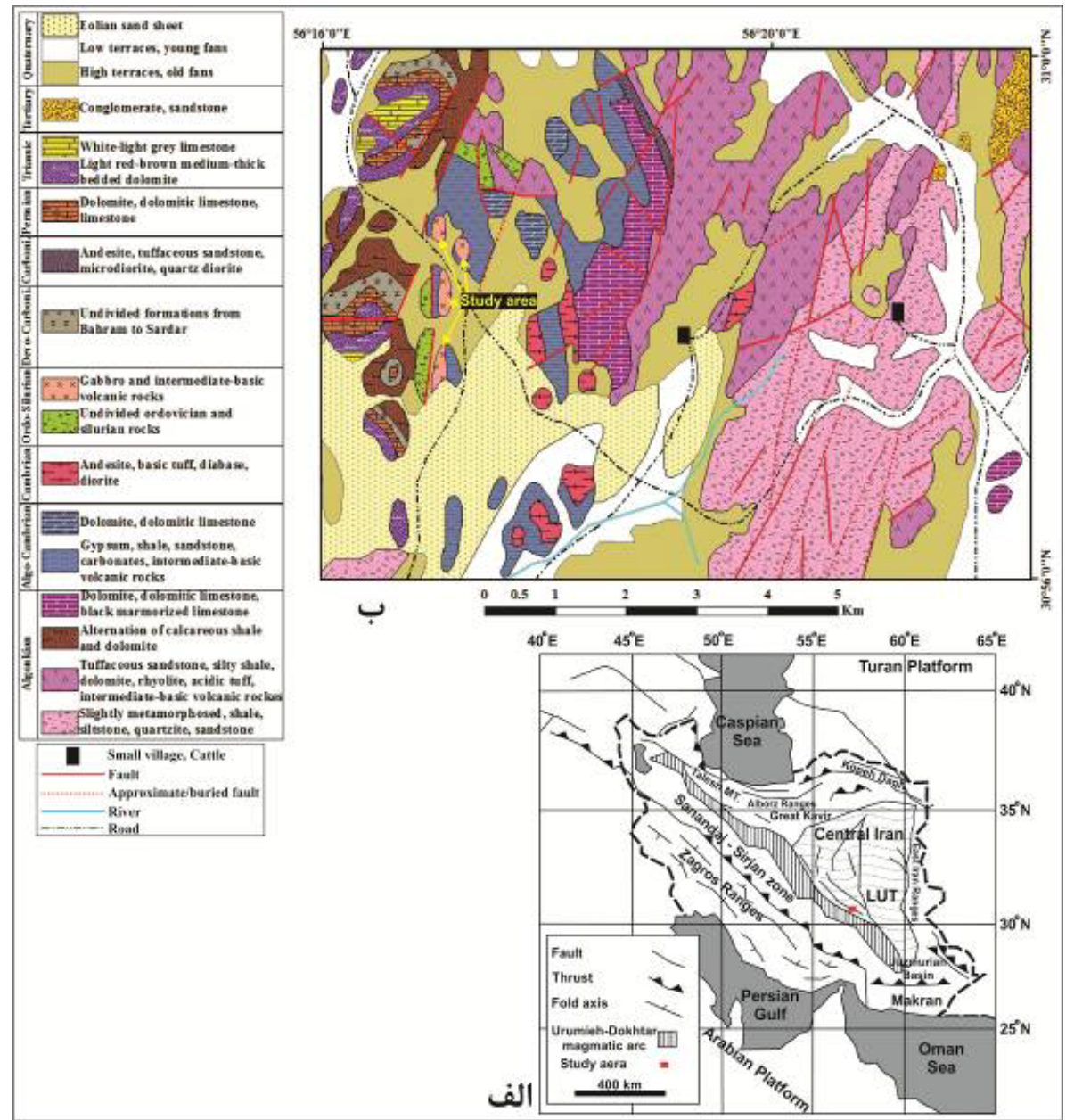

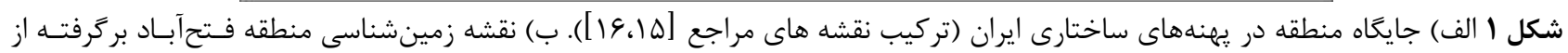

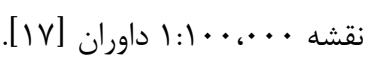
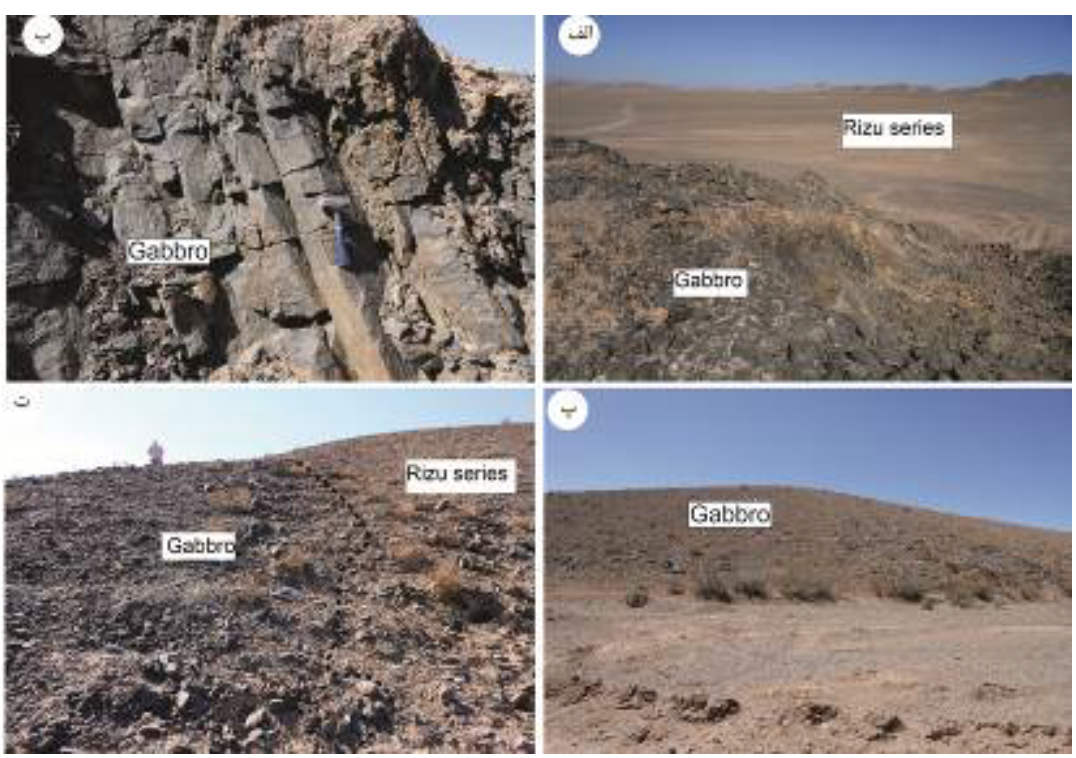

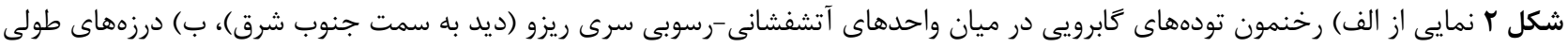

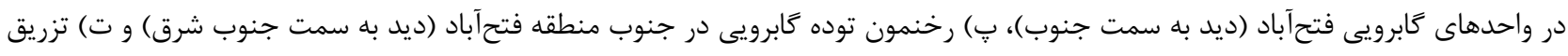
توده كابرويى در ميان واحدهاى سرى ريزو (ديد به سمت جنوب غرب). 
اين كانى در برخى از بلورها ا تا ه ميلىمتر است. در مقاطع

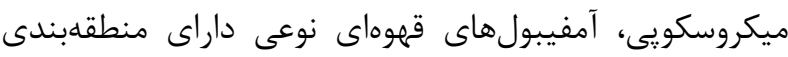
زرد قهوماى يا قرمز قهوهاى و به صورت لوزى تا منشورى شكل

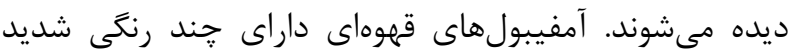

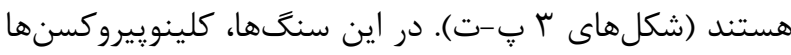

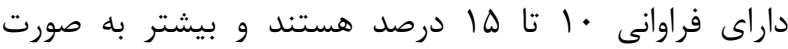

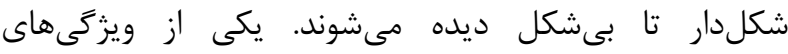

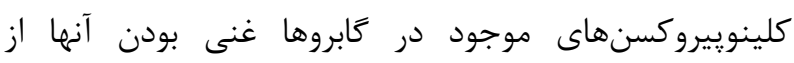

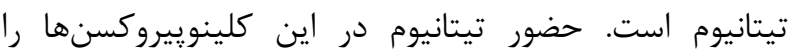

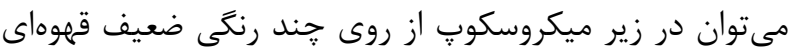

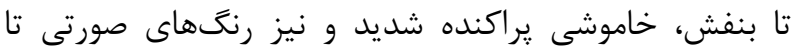
قهوهاى آنها تشخيص داد. غنى بودن كلينوييروكسنها از تئن تئنان

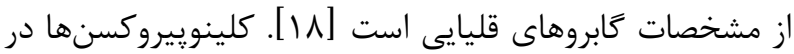
راستاى شكستگىها به كلريتهاى سبز دكرسان شدهاند.
سنغَنَارى

كابروها مهمترين تودههاى نفوذى مافيك در فتحآباد هستند. اين سنگها متوسطدانه بوده و داراى بافت دانه اى هستند

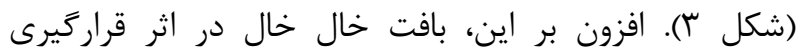

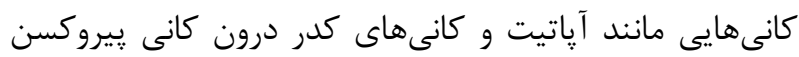

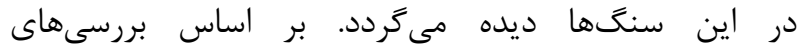

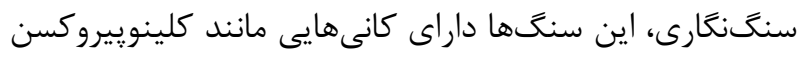

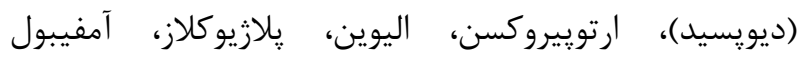

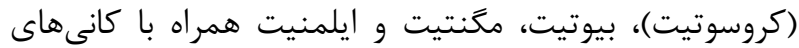
ثانويه مانند كلريت، سرسيت، كلسيت و إيبدوت هستند (شكل - ماند

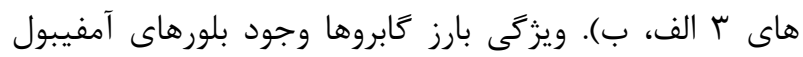

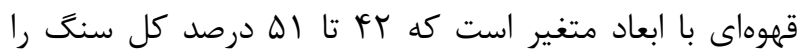

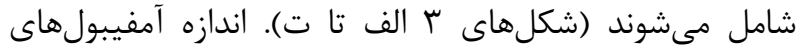

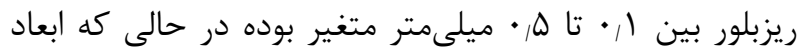
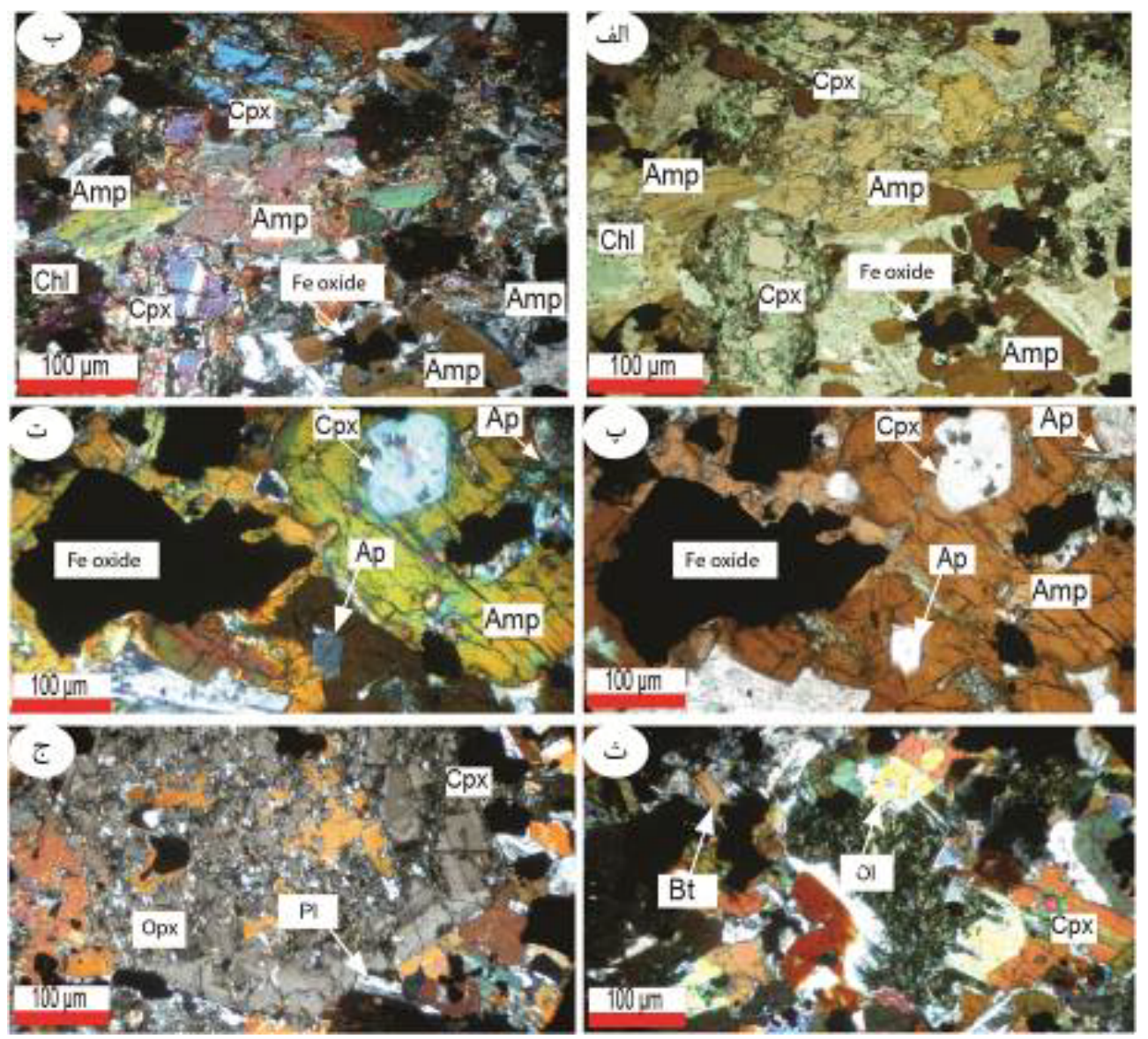

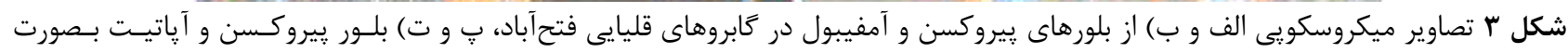

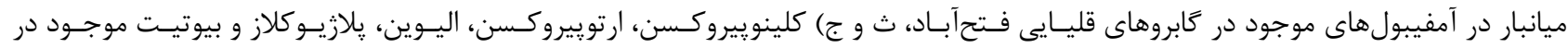

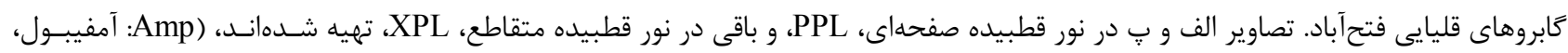
Ap 
شيمى كانى كلينو ييروكسن

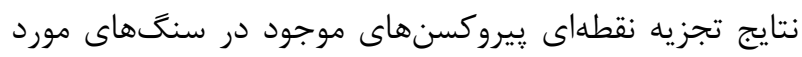
بررسى در جدول الورده شده است. يِيروكسنها از مهمترين

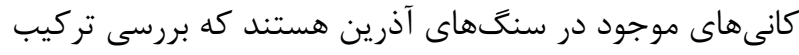
شيميايى و محاسبه فرمول ساختارى آنها مىتواند اطلاعات

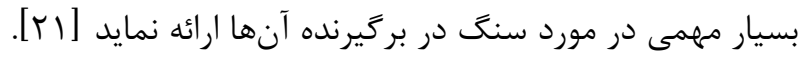

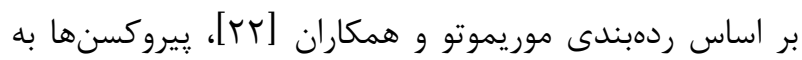
طور كلى در جهار گروه قرار مى گيرند: () ييروكسنهاى Na-Ca بيرو (Quad) Ca-Mg-Fe

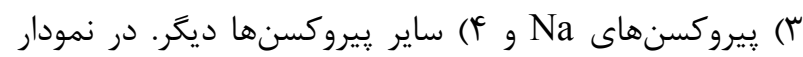
Q = Ca+Mg+Fe و , J = 2Na) Q-J موجود در Fابروهاى فتحآباد در زستره Quad هستند (شكل Q

با توجه به قراركيرى پيروكسنها در گستره Quad،

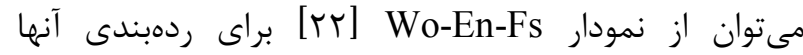

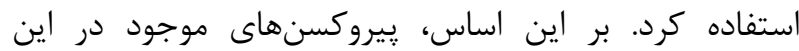

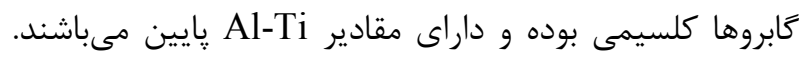

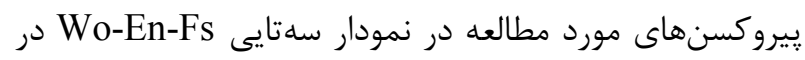

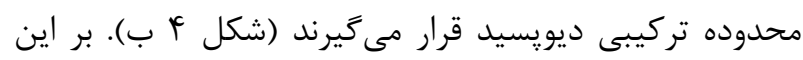
اساس، متوسط تركيب شيميايى كلينوييروكسنها در كابروهاى فتحآباد بصورت

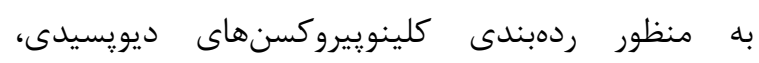

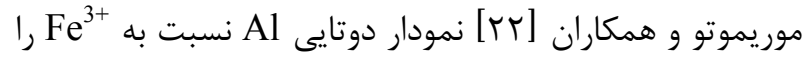
بيشنهاد كردند. در اين نمودار، كلينوييروكسنهاى موجود در دران

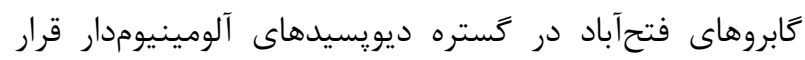

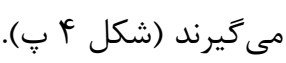

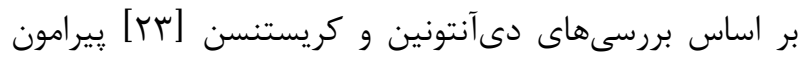

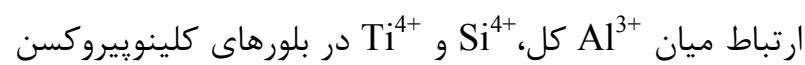

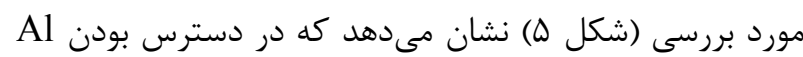
بسيار بيشتر از آن است كه براى تعادل در كمبود Si در در جايخاه

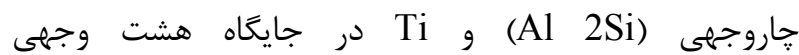

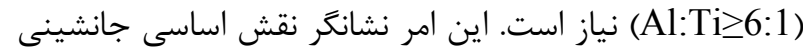
اجزاى هرماكى ( CaAlAlSiO 6 در تركيب كلينوييروكسن موجود در كابروهاى قليايى فتحآباد
ارتوييروكسن با فراوانى س درصد وزنى كانى مافيك ديكر در اين

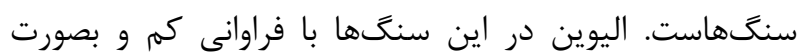

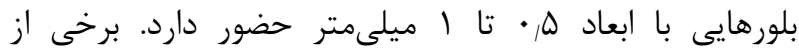

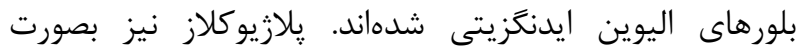

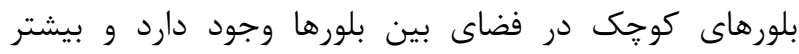
سوسوريتى شده است. بيوتيت بصورت بلورهاى ريز پِيرامون كانىهايى مانند آمفيبول و يِيروكسن ديده مىشود (شكلهاى

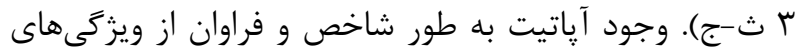
اين سنگهاست كه به شكل سوزنى و منشورى و با فراوانى إنى درصد در اين سنگها و بيشتر به صورت ميانبار در كانىهاى

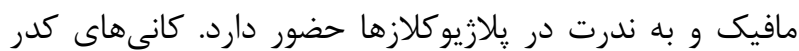

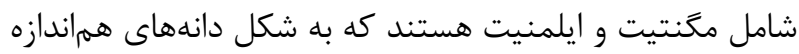
بىشكل در اين سنگها تبلور يافتهاند و با فراوانى ه درصد در

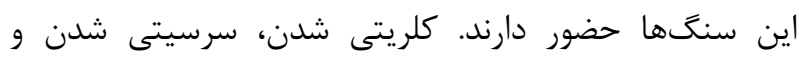

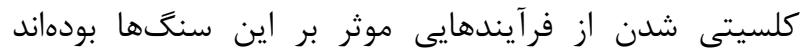

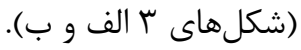

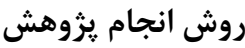

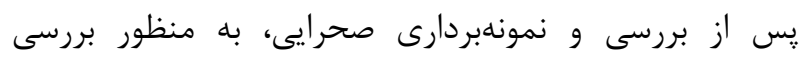

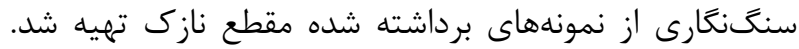

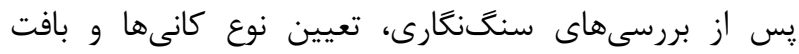

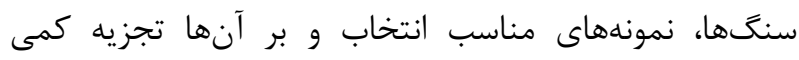

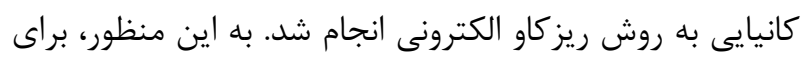

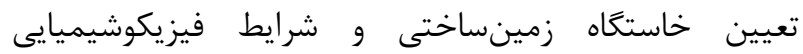
سنَّهاى مورد بررسى با استفاده از تركيب شيميايى پيروكسن تعداد هr نقطه از كانىهاى سازنده آنها (كلينوييروكسنها)

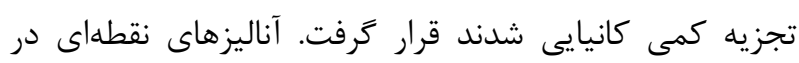

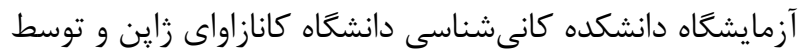
دستغاه JEOL EPMA مدل JXA-8000 با ولتاز شـتابدهنده جريان باريكه 20nA انجام شد. از دادههاى

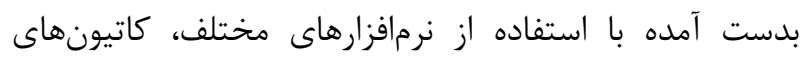
سازنده محاسبه و سيس نمودارهاى لازم رسم و تفسير شدند. براى تفكيك مقدار Fe

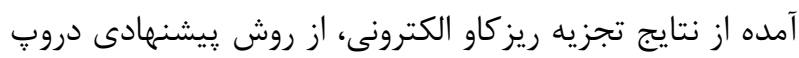

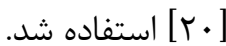


جدول انتايج تجزيه ريزكاو الكترونى بلورهاى كلينوييروكسن موجود در كابروهاى فتحآباد، بر حسب درصد وزنى، همراه با مقدار كاتيونها و درصد

اجزاى سازنده آنها.

\begin{tabular}{|c|c|c|c|c|c|c|c|c|c|c|c|c|}
\hline & P1 & P2 & P3 & P4 & P5 & P6 & P7 & P8 & P9 & P10 & P11 & P12 \\
\hline $\mathrm{SiO}_{2}$ & $r \lambda, \lambda$. & $\gamma \lambda, \lambda$. & $r \Delta, r$. & $f v / \Delta$. & $\Delta \cdot, \cdot$ & $4 \lambda, q 4$ & $f \Delta, r f$ & $r \wedge, \Delta \Delta$ & 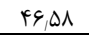 & pv,qv & 99,99 & $r q, \Delta r$ \\
\hline $\mathrm{TiO}_{2}$ & T, KF & $r, \pi$ & $r, \Delta$. & $r, 91$ & 1,99 & $r, 19$ & $r, A F$ & $r, \Delta 9$ & $r, r \Lambda$ & $r, 19$ & $r, \pi r$ & 1,99 \\
\hline $\mathrm{Al}_{2} \mathrm{O}_{3}$ & $\Delta_{,}, r$. & $0, \Gamma \varphi$ & G.T & 981 & $r \cdot r$ & 9 & $\lambda_{1}$. & $9, \pi$ & $\Lambda \leftarrow \Lambda$ & $9, \lambda r$ & $V_{\Delta \Delta V}$ & +90 \\
\hline $\mathrm{Cr}_{2} \mathrm{O}_{3}$ & 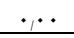 & 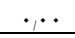 & $\ldots$ & $\ldots$ & $\cdot \ldots$ & $\ldots$ & ${ }^{\prime}, \ldots$ & 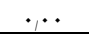 &., 1 & 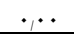 & $\ldots$ & $+\ldots$ \\
\hline $\mathrm{FeO}$ & $9, \pi \mu$ & $q, r \Delta$ & $9, \Delta 1$ & $9, \wedge V$ & $v, 91$ & $\Lambda_{1} \cdot 9$ & $v, \pi 1$ & $9.9 \mathrm{~V}$ & 9,91 & $9, \Lambda \mathrm{F}$ & $9, \mathrm{VV}$ & $9, \pi$ \\
\hline $\mathrm{MnO}$ & .1. & $0,1 Y$ & $0,1 \mathrm{~F}$ &., $1 T$ & $0,1 \mathrm{~V}$ & $0, r$. & $0,1$. & 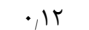 & $\cdots \wedge$ & $\cdots \Lambda$ & $\ldots 9$ &.$\tau \Delta$ \\
\hline $\mathrm{MgO}$ & $|f| V$, & $\|f\| r$, & $\mid r, v V$ & $1 \pi, \pi T$ & $|r,| \lambda$ & $|r,| \Delta$ & $1 T, T H$ & $14,9 \Lambda$ & $1 r_{1} \cdot r$ & $|r, N|$ & 15,9 & $1 T, \Delta q$ \\
\hline $\mathrm{CaO}$ & $r r, r v$ & $r r, 11$ & rr, & $r r_{1} \cdot v$ & Tr,gA & $r 1,99$ & $r(T, 1 \Lambda$ & $r r_{1} \cdot 4$ & 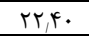 & 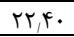 & $r r, 99$ & $r 1,9 V$ \\
\hline $\mathrm{Na}_{2} \mathrm{O}$ & 4 & 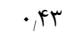 &.$\mu Y$ & $\mu^{\mu \lambda}$ & $.9 \Delta$ & $\cdot 0 q q$ & $\cdot \Delta r$ & .49 & $\cdot \Delta V$ & $\cdot \Delta \Delta$ & 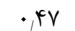 &.$q 4$ \\
\hline $\mathrm{K}_{2} \mathrm{O}$ & 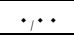 & $\ldots$ & $\ldots$ &., 1 & $\ldots$ & $\ldots$ &., 1 & $\ldots$ & $\ldots$ & $\ldots$ & 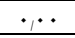 & ${ }_{i}, \cdot$ \\
\hline $\mathrm{NiO}$ & $\because$ & $\ldots$ & $\ldots$ & $\ldots$ & $\ldots$ & $\ldots$ & $\ldots r$ & $\ldots 1$ & $\mu r$ & $\ldots$ & $\ldots$ & $\ldots$ \\
\hline \multirow{2}{*}{\multicolumn{13}{|c|}{ 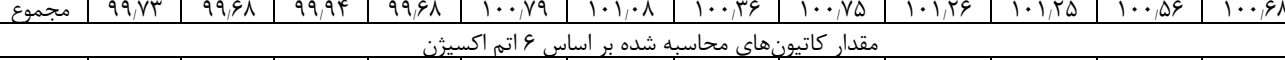 }} \\
\hline & & & & & & & & & & & & \\
\hline $\mathrm{Si}$ & $1, \lambda 1$ & $1, \lambda 1$ & $1, v \Lambda$ & $1, V \mathrm{~V}$ & 1,19 & $1,1$. & $1,9 \Lambda$ & $1, v \wedge$ & $1, \gamma$ & $1, v \Delta$ & $1, V r$ & $1, \lambda \mu$ \\
\hline Ti & $\because v$ & $\% v$ & $\because v$ & $\% v$ & $\because \bullet \Delta$ & .1 .4 & .111 & $\because \%$ & .1 & 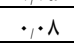 & $\because 99$ & $\because \Delta$ \\
\hline $\mathrm{Al}$ &.$\pi r$ & $0, \pi r$ &., 19 &., 49 &., $1 \Lambda$ &., 19 & $\cdot \pi \wedge$ &.$\Gamma V$ &., 49 &.,$\pi 9$ &.$\pi r$ &.,$\pi$ \\
\hline $\mathrm{Cr}$ & $\ldots$ & 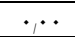 & $\ldots$ & $\ldots$ & $\ldots$ & $\ldots$ & $\ldots$ & $\ldots$ & $\ldots$ & ${ }_{\cdots}$ & $\ldots$ & $\ldots$ \\
\hline $\mathrm{Fe}^{3+}$ & $\because \Delta$ & $\because \Delta$ & .1 .4 & .1 .9 & .1 .4 & .1 .4 & .1 .9 & $\because \Delta$ & $\therefore 9$ & $\because \wedge$ & $\because 1$ & $\because v$ \\
\hline $\mathrm{Fe}^{2+}$ & .10 & .10 &., $1 f$ & .10 &., 19 &., 11 &., 14 &., $\mathrm{~V}$ &.,$\pi$ & . &., $1 Y$ & $\cdot \pi r$ \\
\hline $\mathrm{Mn}$ & $\ldots$ & $\ldots$ & $\ldots$ & $\ldots$ &.,$\cdot 1$ &.,$\cdot 1$ & $\ldots$ & $\ldots$ & $\ldots$ & ${ }_{\mu}$ & $\ldots$ &., 1 \\
\hline $\mathrm{Mg}$ & 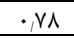 & $\cdot, v \wedge$ & $\cdot, \sqrt{ }, \mathrm{s}$ & $\cdot v^{f}$ & $\cdot, V r$ & $\cdot, V r$ &., $9 \Lambda$ & $\cdot v \Delta$ & $\cdot, V_{1}$ & - $v_{\Delta}$ & $\cdot, V K$ & . v \\
\hline $\mathrm{Ca}$ &.$\wedge 9$ & $\cdot \cdot \wedge \Lambda$ & $\cdot \wedge 9$ & $\cdot, \wedge \Lambda$ & .9. & $\cdot \cdot \wedge 9$ & $\cdot \cdot \Lambda \Lambda$ & $\cdot \cdot A V$ & $\cdot, \Lambda \Lambda$ & $\cdot \cdot \wedge \Lambda$ & .9. & $\cdot A V$ \\
\hline $\mathrm{Na}$ & $\because r$ & $\cdot r r$ &.,$r$ & $\cdot, r r$ & $\because \cdot \Delta$ & 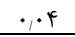 & $\because \varphi^{4}$ & $\because r$ & 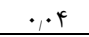 & $\ldots \varphi^{q}$ & $\because r$ & $\ldots F$ \\
\hline $\mathrm{K}$ & $\ldots$ & $\ldots$ & $\ldots$ & $\ldots$ & $\ldots$ & $\ldots$ & $\ldots$ & $\ldots$ & $\ldots$ & $\ldots$ & $\ldots$ & \\
\hline مجموع & $F_{1} \cdot \cdot$ & $F_{1} \cdot \cdot$ & $f, \cdot$ & $F_{1} \cdot \cdot$ & $f_{i} \cdot \cdot$ & $r_{i} \cdot \cdot$ & $r_{1} \cdot \cdots$ & $r_{i} \cdot \cdot$ & $F_{1} \cdot \cdot$ & $F_{i} \cdot \cdot$ & $f_{i} \cdot \cdot$ & $f_{i} \cdot \cdot$ \\
\hline$\% \mathrm{En}$ &.,$k T$ & $0,4 \pi$ & $0.4 Y$ & $\cdot, \mu T$ & 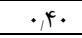 & 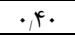 & 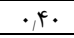 &.,$Y T$ & $0.4 T$ &., $4 \pi$ &.+41 &., 49 \\
\hline$\% \cdot F s$ & $\because \wedge$ & $\because \wedge$ & $\because \wedge$ & $\because \wedge 1$ & .1. & .1. & $\because \wedge$ & $\because 99$ & $\because v$ & $\because v$ & $\because v$ &.,$\| r$ \\
\hline$\%$ Wo & .099 &., 49 & $\cdot \Delta \cdot$ & $\cdot \Delta \cdot$ & $\cdot \Delta \cdot$ &., 99 & $\cdot \Delta r$ & .499 & $\cdot(\Delta)$ & $\cdot \Delta \cdot$ & $\cdot \Delta r$ & .099 \\
\hline
\end{tabular}

\begin{tabular}{|c|c|c|c|c|c|c|c|c|c|c|c|}
\hline & P13 & P14 & P15 & P16 & P17 & P18 & P19 & P20 & P21 & P22 & P23 \\
\hline $\mathrm{SiO}_{2}$ & $\Delta .9 \Lambda$ & $q v, q r$ & 49,11 & $\varphi \wedge, 9 Y$ & $q 9,4$. & FY, & $F V, A F$ & $q q, p$. & $p 9,99$ & $F, r q$ & 99,19 \\
\hline $\mathrm{TiO}_{2}$ & $1,9$. & r,VY & $r, 91$ & 1,99 & $r, r \Lambda$ & $r, 95$ & $r, 99$ & $r .9$ & 1,99 & $T, A F$ & $T, \pi$ \\
\hline $\mathrm{Al}_{2} \mathrm{O}_{3}$ & $r, v 1$ & $9, \Delta$. & $\Lambda, r \Lambda$ & $9 \times 9$ & $\Delta, r \Lambda$ & $9,4 \lambda$ & 9,11 & $f, v f$ & $r, \Delta)$ & $9, \Lambda T$ & $0, \pi f$ \\
\hline $\mathrm{Cr}_{2} \mathrm{O}_{3}$ & $\ldots$ & $\ldots$ & $\ldots$ & $\ldots$ & $\ldots$ & $\ldots$ &., 1 & $\ldots$ & $\ldots$ & $\ldots$ & $\ldots$ \\
\hline $\mathrm{FeO}$ & 9,1 & $9 \Delta Q$ & $V, T V$ & $\lambda, \varphi_{i} \lambda$ & $9, \Delta q$ & 991 & $99 \mathrm{~V}$ & $9, \Lambda \Delta$ & $9 \Delta T$ & $9,9 \mathrm{~V}$ & 9,91 \\
\hline $\mathrm{MnO}$ & .19 &., 11 &., $1 Y$ & $0.1 \mathrm{~V}$ &., $1 T$ & .110 & 0.11 & .111 & 0.014 &.,$\pi T$ & $0.1 T$ \\
\hline $\mathrm{MgO}$ & $1 F, 9 T$ & $\mid r, v f$ & $\mid \pi, v$. & $|r| r$, & IF,TY & $\| r, \Delta$. & $|r, \Delta|$ & $\mid F, r$. & $1 F, 4 \lambda$ & $\mid r, 19$ & 19,49 \\
\hline $\mathrm{CaO}$ & Tr,f. & $r Y, \Delta G$ & $T r, T V$ & $r, v_{\Delta}$ & $r, r \Lambda$ & 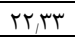 & $r r, \Delta \Lambda$ & Tr,TS & TK,F & Tr,TS & $T r, I T$ \\
\hline $\mathrm{Na}_{2} \mathrm{O}$ &.+4 &.$+4 \Delta$ & $\cdot \Delta \phi$ &., $9 T$ & $.4 r$ & .148 &.$+4 \Delta$ &.$+\wedge$ &.$\mu \Lambda$ & .499 & $.4 r$ \\
\hline $\mathrm{K}_{2} \mathrm{O}$ & $\cdot, \cdot$ & $\ldots$ & 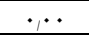 & $\ldots$ & $\ldots$ &., 1 & $\ldots$ &., 1 & $\ldots$ & $\ldots$ & $\ldots$ \\
\hline $\mathrm{NiO}$ & $\ldots$ & $\ldots$ & .1 & $\ldots$ &.$\cdot 1$ & $\ldots$ & $\ldots$ & $\ldots 1$ & $\ldots$ &.$\cdot 1$ & $\ldots$ \\
\hline \multirow[t]{2}{*}{ ع مج } & $1 \ldots 911$ & $1 \ldots 9 \Delta$ & $1 \cdot 1 \cdot 1 \cdot 1$ & $1.1,4 \lambda$ & $1 \ldots v g$ & 99,94 & $1 \ldots .$. & $1 \ldots \mu r$ & $1 \ldots, k r$ & $1 \ldots, r \Delta$ & $1, \ldots, 49$ \\
\hline & & & & كاتم اكسي & لهـ بر اسارد & محاسبه & كاتيونها: & & & & \\
\hline $\begin{array}{l}\mathrm{Si} \\
\end{array}$ & 1,19 & 1,19 & $1, v \cdot$ & 1,19 & $1, \lambda 1$ & $1, Y V$ & $1, V v$ & $1, \lambda \mu$ & $1, \Lambda f$ & $1, v \Delta$ & $1,1,1$ \\
\hline $\mathrm{Ti}$ & $\ldots \varphi$ & $\because \wedge$ & .1. & $\because \Delta$ & .14 & $\% v$ & $\% v$ & 1.9 & .1 .9 & 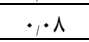 & 1.4 \\
\hline $\mathrm{Al}$ & .19 &.,$r \Lambda$ &., 48 &.$\Gamma \Lambda$ & 0 &.$r \Lambda$ &.$\pi V$ &.,$\pi$ &.,$r$. & 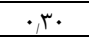 &.$\pi r$ \\
\hline $\mathrm{Cr}$ & $\ldots$ & $\ldots$ & $\ldots$ & $\ldots$ & $\ldots$ & $\ldots$ & $\ldots$ & $\ldots$ & $\ldots$ & $\ldots$ & $\ldots$ \\
\hline $\mathrm{Fe}^{3+}$ & $\because \Delta$ & $\because v \varphi^{4}$ & $\ldots 9$ & $\cdots 1$ & .1 .9 & $\because v$ & $\because v$ & $\cdots \Delta$ & $\ldots \varphi$ & $\cdots v$ & $\because \Delta$ \\
\hline $\mathrm{Fe}^{2+}$ & .10 & .014 & .14 &., 11 & .10 &., 14 &., 14 & .11 & .19 &., 14 & .10 \\
\hline $\mathrm{Mn}$ & $\ldots$ & $\ldots$ & $\ldots$ &. .1 & $\ldots$ & $\ldots$ & $\ldots$ & $\ldots$ & $\ldots$ & $\ldots$ & $\ldots$ \\
\hline $\mathrm{Mg}$ & $\cdot \cdot \wedge 1$ &.$v \Delta$ &.$v$ & 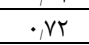 & 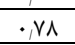 &.$v \Delta$ &.$v \Delta$ & $\cdot, \gamma \Lambda$ & $\cdot \lambda \cdot$ & 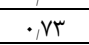 & . V9 \\
\hline $\mathrm{Ca}$ & $\cdot, \wedge \Lambda$ & $\cdot \cdot \wedge 9$ & $\cdot \cdot \Lambda \Lambda$ & $\cdot \wedge \Delta$ & $\cdot, \Lambda \Lambda$ & $\cdot \cdot \wedge 9$ & .9. & $\cdot, \Lambda \Lambda$ & $\cdot \cdot 19$ & $\cdot \wedge 9$ & $\cdot \wedge V$ \\
\hline $\mathrm{Na}$ & $\because r$ & 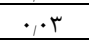 & $\ldots \varphi$ & $\ldots \varphi$ & 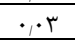 & 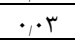 & $\because r$ & $\% r$ & 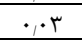 & $\because r$ & $\% r$ \\
\hline $\mathrm{K}$ & $\ldots$ & $\ldots$ & $\ldots$ & $\ldots$ & $\ldots$ & $\ldots$ & $\ldots$ & $\ldots$ & $\ldots$ & $\ldots$ & $\ldots$ \\
\hline مجموع & $r, \cdot$ & $r_{i} \cdot$. & $r_{i} \cdot$. & $f_{1} \cdot \cdot$ & $r, \cdot$ & $r_{1} \cdot$. & $r_{i} \cdot$. & $r_{1} \cdot$. & $r_{1} \cdot$. & $r_{i} \cdot$. & $r_{1} \cdot \cdot$ \\
\hline$\%$ En & .44 & .44 &.$(+4)$ &.,+1 &.$\mu r$ &.$\mu r$ &.,$\mu T$ &.,$\mu r$ &.,$\mu r$ & $., 4)$ &., 44 \\
\hline$\%$ Fs & $\cdots 1$ & $\because \cdot v$ & $\because \wedge$ & .1. & $\because \wedge$ & $\because \wedge$ & $\because \Lambda$ & $\ldots 9$ & $\cdots 9$ & $\cdots 1$ & $\cdots 1$ \\
\hline$\%$ Wo &.$\mu \lambda$ & $\cdot{ }_{\cdot \Delta \cdot}$ & $. \Delta \mid$ & .199 &.+49 & $\cdot \Delta \cdot$ & $\cdot \Delta \cdot$ &.$\mu \Lambda$ & $.4 \lambda$ & $\cdot(\Delta)$ & 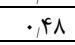 \\
\hline
\end{tabular}

ادامه جدول إما 
ادامه جدول

\begin{tabular}{|c|c|c|c|c|c|c|c|c|c|c|c|c|}
\hline & P24 & P25 & P26 & P27 & P28 & P29 & P30 & P31 & P32 & P33 & P34 & P35 \\
\hline $\mathrm{SiO}_{2}$ & $F \wedge, q \mathrm{~V}$ & $r \wedge, r$. & $\langle\wedge, 1 \Lambda$ & $r q, r^{4}$ & $F 9,51$ & $4 q, \pi r$ & $4 q, Y^{4}$ & $\Delta \cdot v \wedge$ & $\Delta \cdot r$. & 99,99 & $\Delta \cdot, r$. & 49,94 \\
\hline $\mathrm{TiO}_{2}$ & $r, r q$ & $T, Q T$ & $r, q V$ & $r, r \Lambda$ & $r, r q$ & $1, V V$ & $1, \Lambda r$ & $1, \pi 9$ & $1, \Delta \Delta$ & $1,9 \pi$ & 1,44 & 1,94 \\
\hline $\mathrm{Al}_{2} \mathrm{O}_{3}$ & $\Delta, v q$ & 8, . & 8,44 & $\Delta, v \Lambda$ & $\Delta, g q$ & $\Delta, r 1$ & $\Delta_{1}{ }_{\Lambda} \Lambda$ & $r, 99$ & $f, v V$ & $Q_{1} \cdot 9$ & $F, 11$ & $\Delta_{1} \cdot 9$ \\
\hline $\mathrm{Cr}_{2} \mathrm{O}_{3}$ & 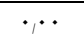 &.+1 & 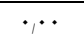 & 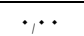 &.$\cdot r$ & 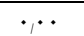 &.. & $\ldots$ & 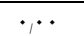 & $\ldots$ & 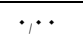 & 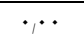 \\
\hline $\mathrm{FeO}$ & $9, \Delta \mathrm{V}$ & g,VG & $9, \mathrm{Vr}$ & 9,99 & $9, \Delta G$ & 1,19 & $\Lambda, \wedge \Delta$ & $9,4 \Lambda$ & $9,4 \pi$ & $9, \vee 9$ & 9,49 & $9,9$. \\
\hline $\mathrm{MnO}$ & .1. &. .9 & $.1 \mathrm{~F}^{\mathrm{s}}$ & .1. & $.1 K$ & $\cdot r \Delta$ & . r. &.$\mu$. &., 19 &.,$T^{\prime}$ & $\cdot r \Delta$ &.,$\pi V$ \\
\hline $\mathrm{MgO}$ & $1 r, 9 \mathrm{~V}$ & $1 r, 95$ & $1 \pi, v q$ & $1 F, \pi \Delta$ & $|f| r$, & $1 T, 49$ & $1 T, \Delta \varphi$ & $1 T, V q$ & $1 T, \pi \Delta$ & $11, \mathrm{Vr}$ & 11,99 & $|r,|^{F}$ \\
\hline $\mathrm{CaO}$ & $r K, Y \Lambda$ & $Y T, Y F$ & $r u, r q$ & $r T, Y \Lambda$ & $r r_{1} \cdot r$ & $r 1,9 r$ & $r 1,99$ & $r I, F T$ & 91,19 & $r 1, r \Delta$ & $r 1, r q$ & $r \mid, \Delta \varphi$ \\
\hline $\mathrm{Na}_{2} \mathrm{O}$ &.,$\mu V$ & $\cdot \Delta \cdot$ & $.4 \pi$ & .49 & 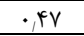 & .99 & $.9 \pi$ &., 94 &., 99 & $\cdot, \mathrm{VI}$ & $.9 \pi$ & $.9 \Lambda$ \\
\hline $\mathrm{K}_{2} \mathrm{O}$ & $\ldots$ & $\ldots$ & $\ldots$ & $\ldots$ & $\ldots$ & ${ }_{*}, \cdot$ & $\ldots$ & $\ldots$ & $\ldots$ & $\ldots$ & $\ldots$ & $\ldots$ \\
\hline $\mathrm{NiO}$ &. .1 &.$\cdot r$ &. .1 & $\ldots$ & $\ldots$ &.$\cdot r$ & $\ldots$ & $\ldots$ & 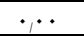 & $\ldots$ & $\ldots$ &. .1 \\
\hline مجموع & $1, \cdots, 4)$ & $1 \cdots, v \Delta$ & $1 \cdots, v \Delta$ & 101,11 & $1 . ., 4 \pi$ & $1 \cdots, \Delta q$ & $1 \ldots,+1$ & $1, ., 94$ & $1 \ldots, k 4$ & $1 \cdots, r \Delta$ & $1 \cdots, r^{\prime}$ & $1 \cdots \Delta V$ \\
\hline \multicolumn{13}{|c|}{ مقدار كاتيونهاى محاسبه شده بر اساس 9 اتم اكسيرن } \\
\hline $\mathrm{Si}$ & $1,1$. & $1, \mathrm{VA}$ & $1, \mathrm{VV}$ & $1, \lambda$. & $1, \lambda 1$ & $1, \lambda r$ & $1, \lambda r$ & $1,1 \Lambda$ & $1, \Lambda V$ & 1,19 & $1,1 \mathrm{~V}$ & $1, \wedge \Delta$ \\
\hline $\mathrm{Ti}$ & $\cdot \cdot \cdot v$ & $\cdot \cdot \cdot V$ & $\because \cdot \mathrm{V}$ &.$\cdot \cdot \mathrm{V}$ &.$\cdot v$ & $\because \cdot \Delta$ & $\cdot \cdot \cdot \Delta$ &.$\% 4$ & $\cdot \cdot \varphi^{4}$ & $\cdot \cdot \omega$ & 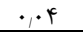 & $\cdot \cdot \Delta$ \\
\hline $\mathrm{Al}$ &.,$T_{\Delta}$ &.$T V$ &. $\mathrm{r} \Lambda$ &.,$r \Delta$ &.,${ }^{.} \mathrm{F}$ &.$\pi r$ & 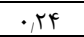 & $.1 \mathrm{~V}$ &.,$r 1$ &.,$\pi$ & $.11 \mathrm{~A}$ &.,$\pi$ \\
\hline $\mathrm{Cr}$ &.. &..$\cdot$ &.. &.. &.. & $\ldots$ & $\ldots$ & 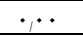 & $\ldots$ & $\ldots$ &..$\cdot$ &.. \\
\hline $\mathrm{Fe}^{3+}$ &.$\cdot \mathrm{V}$ &.$\cdot \mathrm{V}$ &. .94 & .1 .9 &.$\cdot 4$ &., .9 & $\because \cdot \Delta$ &.$\cdot r$ &.$\cdot r$ &.$\cdot r$ &., 4 & $\because \cdot 0$ \\
\hline $\mathrm{Fe}^{2+}$ & $.11 \mathrm{~F}$ & $.1 \mathrm{~F}$ & .14 & .10 & $.1 \mathrm{~V}$ & $\cdot, r_{1}$ & $0, \pi r$ & 0,48 & . $T V$ & $\cdot, r \Lambda$ & $\cdot r \Delta$ & $\cdot r \Delta$ \\
\hline $\mathrm{Mn}$ & $\ldots$ & 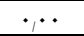 & $\ldots$ & $\ldots$ & $\ldots$ &. .1 &. .1 &., 1 &. .1 &. .1 &. .1 &. .1 \\
\hline $\mathrm{Mg}$ & - VV & - Vq & - $v \Delta$ & $\cdot \mathrm{VA}$ & - VV & .99 & .99 & $\cdot v 1$ & .91 & .90 & - v. & $.9 \mathrm{~V}$ \\
\hline $\mathrm{Ca}$ &.$\wedge 9$ & $\cdot \Delta V$ & $\cdot \wedge \Lambda$ & $\cdot \wedge V$ & $\cdot \Delta V$ & $\cdot \cdot \wedge \mathrm{V}$ & $\cdot \cdot \wedge \varphi$ & $\cdot \wedge \Delta$ & $\cdot \Delta F$ & $\cdot \wedge \Delta$ & $\cdot \wedge \Delta$ & 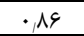 \\
\hline $\mathrm{Na}$ & $\cdot \cdot r$ &.$\cdot{ }^{4}$ &.$\cdot r$ &.$\cdot r$ &.$\cdot r$ & $\because \cdot \Delta$ &.$F^{k}$ & $\because \Delta$ & $\because \cdot \Delta$ & $\because \cdot \Delta$ & $\because \theta$ & $\because \Delta$ \\
\hline $\mathrm{K}$ & $\ldots$ & 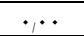 & $\ldots$ & $\ldots$ & $\ldots$ & $\ldots$ & $\ldots$ & $\ldots$ & $\ldots$ & $\ldots$ & $\ldots$ & $\ldots$ \\
\hline مجموع & $f_{1}, \cdot$ & $f_{1} \cdot \cdots$ & $f, \cdot$ & $f, \cdot$ & $f, \cdot$ & $f_{1} \cdot \cdot$ & $f_{1} \cdot \cdot$ & $f_{1}, \cdot$ & $r, \cdot$ & $r, \cdot$ & $r, \cdot$ & $f_{1} \cdot \cdot$ \\
\hline$\%$ En & 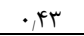 & $.4 \pi$ &.,$H T$ & . & $.4 \pi$ &., 49 &., 49 &.$\pi 9$ &.$\mu \Lambda$ & .49 &., 49 &.$\mu \Lambda$ \\
\hline$\% \mathrm{Fs}$ & $\because \cdot 1$ & 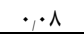 & $\because \cdot 1$ & $\because \cdot 1$ & .1 .9 &., $1 K$ & . & .10 & .10 & .19 & $.11 \mathrm{f}$ & $.1 f$ \\
\hline$\%$ Wo & $\cdot \Delta \cdot$ &., 49 & $\cdot \Delta$ & .099 &.$+4 \lambda$ & .49 &.$+4 \lambda$ &., $4 \mathrm{~V}$ & $.4 \mathrm{~V}$ &., $4 \lambda$ &., $4 V$ & $\cdot,+\lambda$ \\
\hline
\end{tabular}
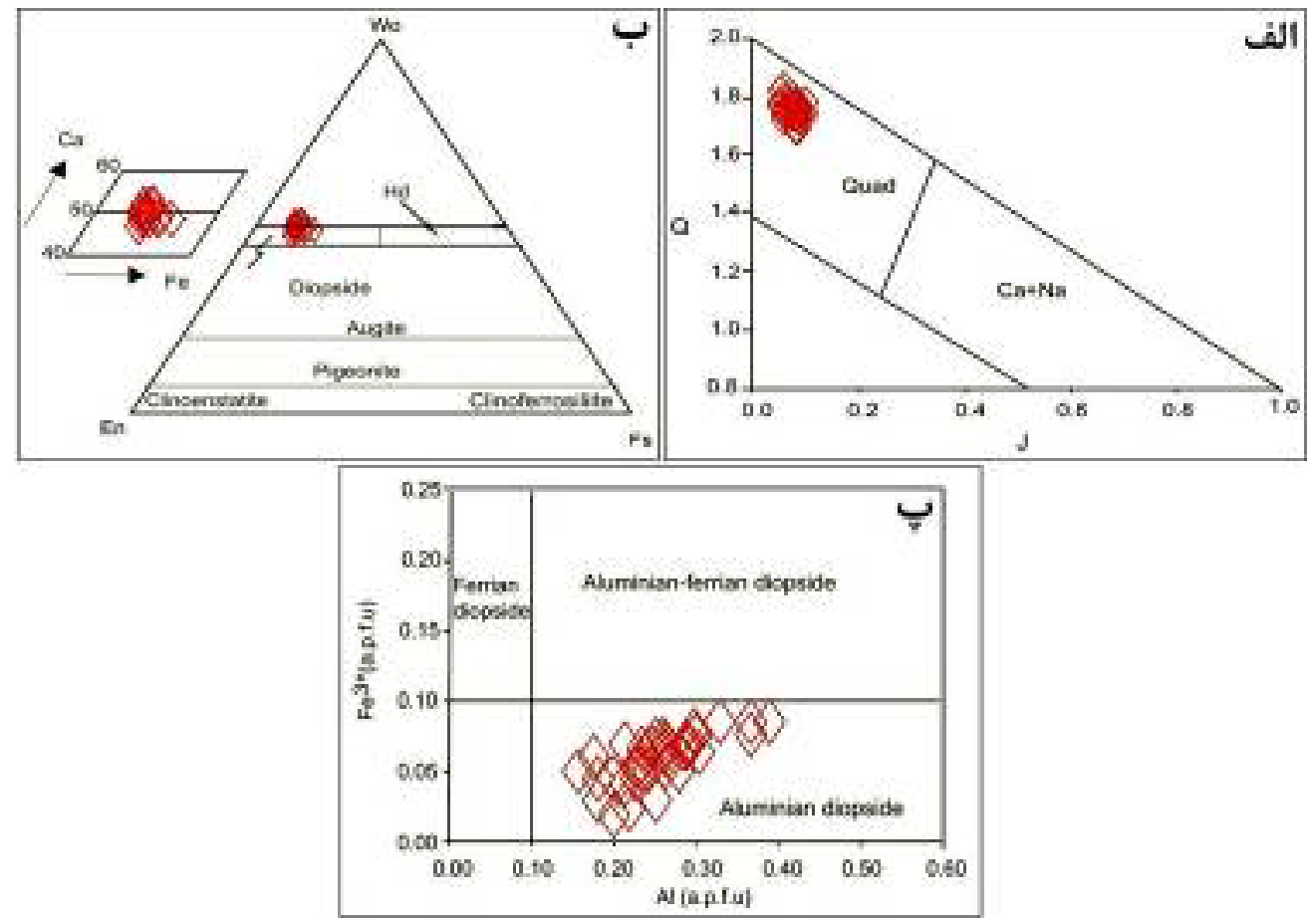

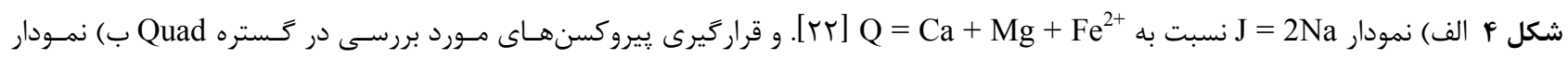

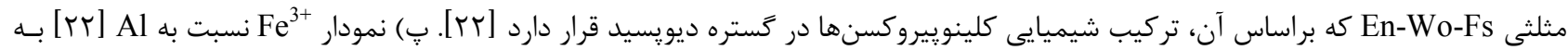
منظور ردهبندى بيروكسنهاى فتحآباد. 

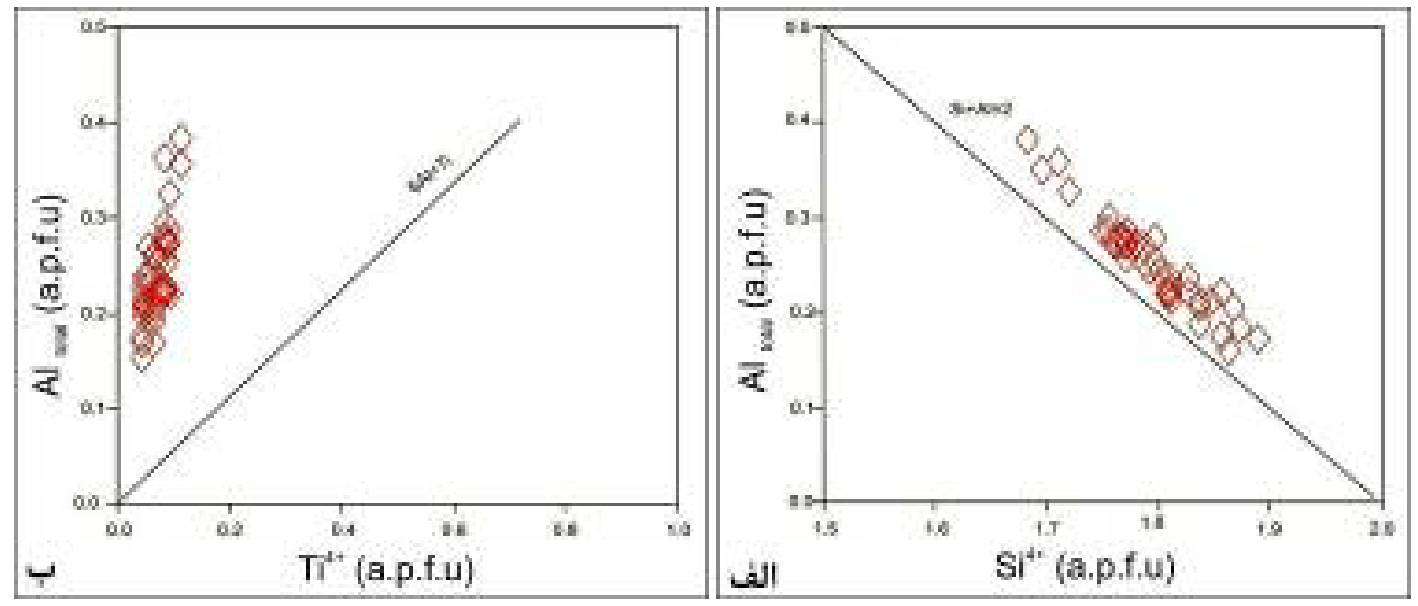

شكل ه الف) نمودار Si نسبت به Al كل و ب) نمودار Ti نسبت به Al كل براى كلينوييروكسنهاى فتحآباد [rr].

بدين منظور، جايعاه يِيروكسنهاى فتحآباد در نمودارهاى ي بيشنهادى توسط لى باس $\mathrm{TiO}_{2} \mathrm{O}_{3}$

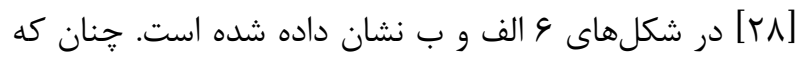

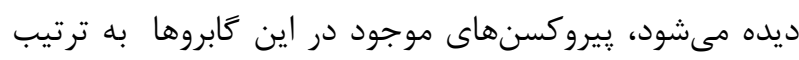

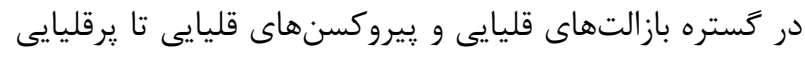

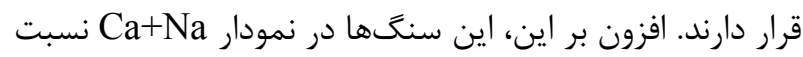

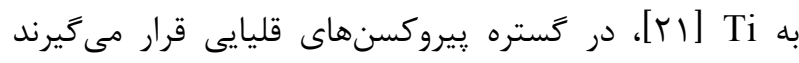

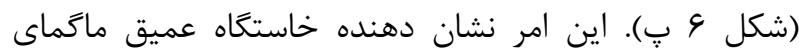
ميزبان اين كانىهاست.
تعيين سرى ماكمايى به اعتقاد بسيارى از يزوهشكران، تركيب شيميايى يُيروكسن به

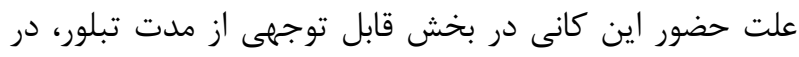

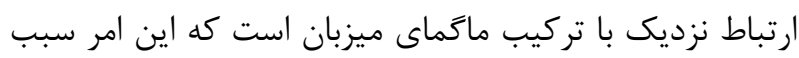

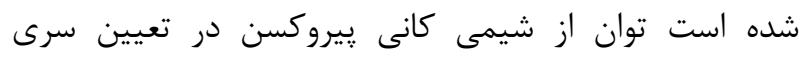

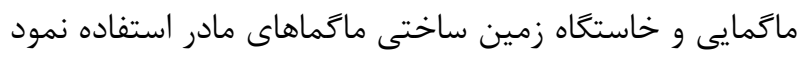

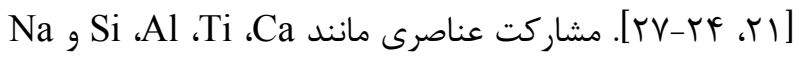
در شبكه كانى كلينوييروكسن وابستكى شديدى به درجاند

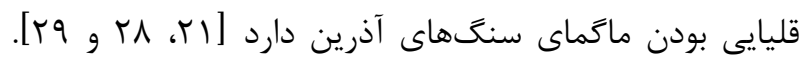
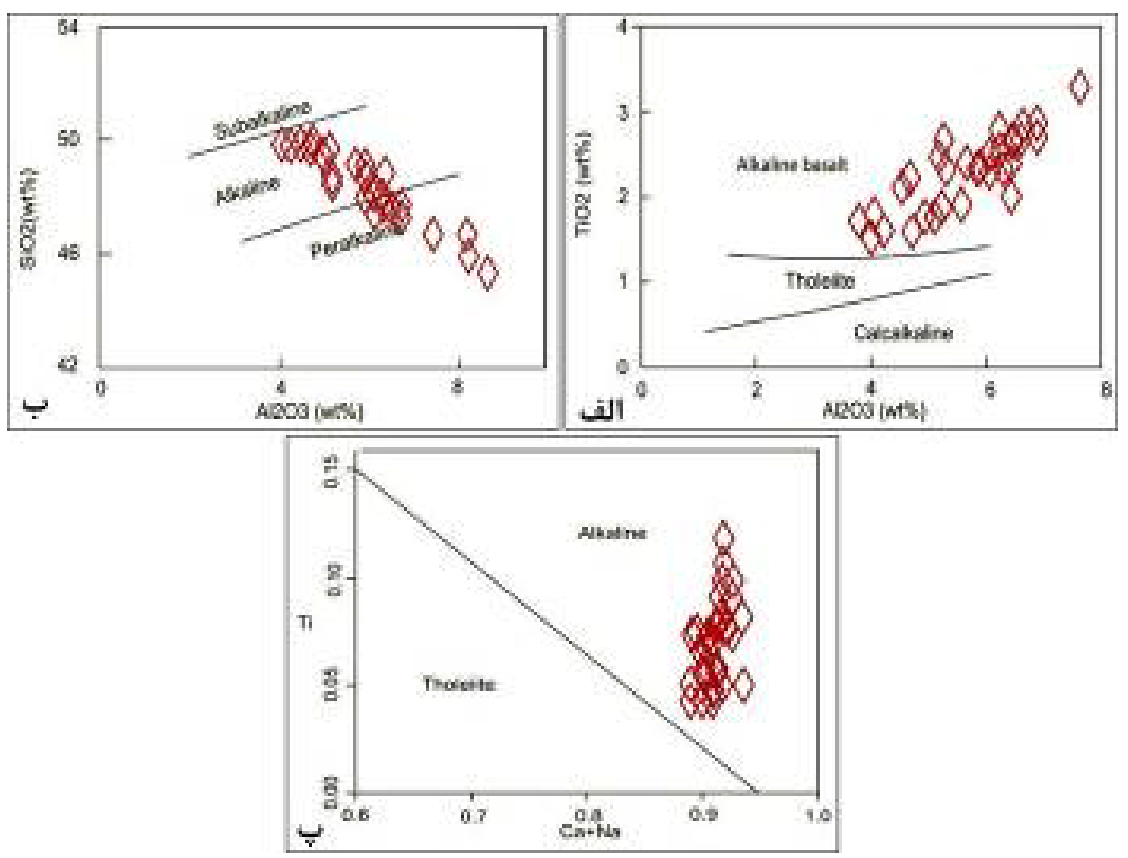

شكل 4 نمودارهاى تعيين سرى ماكمايى مذاب مادر كلينوييروكسنهاى موجود در كابروهاى فتحآباد. نمودارهاى الف و ب از لىباس [^یا] بوده و

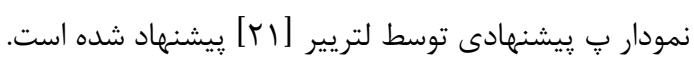


$(0.0029 * \mathrm{MgO})+(0.0085 * \mathrm{CaO})+(0.016 *$ $\mathrm{Na}_{2} \mathrm{O}$ )

ثيروكسنهاى گابروهاى فتحآباد در اين نمودار در كستره بازالتهاى قليايى درون صفحهاى قرار دارند (شكل V الف). افزون بر اين، نمودار مثلثى $\mathrm{SiO}_{2} / 100-\mathrm{TiO}_{2}-\mathrm{Na}_{2} \mathrm{O}$

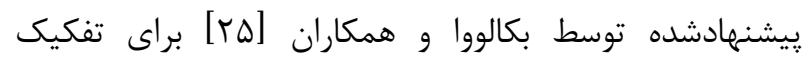
خاستگاه زمينساختى يروكسنهاى موجود در كَابروهاى فتحآباد نشان مىدهد كه اين كلينوييروكسنها در كستره تركيبى پيروكسنهاى قليايى درون صفحهاى موجود در بازالتهاى ناشى از فعاليت تنوره در منطقه ايسلند قرار دارند

$$
\text { (شكل V ب). }
$$

عوامل ترموديناميكى مؤثر در تبلور ييروكسنهاى فتح آباد

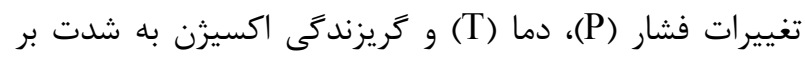
تاريخجه تبلور و تركيبات كانى پيروكسن در سيستمهاى

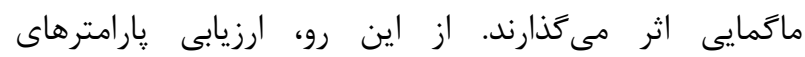
ترموديناميكى از مدلهاى فعاليت با استفاده از تركيبات كانيايى به منظور بازسازى تاريخجه ماتمايى نمونههاى مورد بررسى ضرورى است. اين يارامترها در ادامه به تفصيل بررسى بـى بـى شدهاند.
خاستكاه زمينساختى تركيب شيميايى كلينوييروكسن وابسته به تركيب شيميايى و خاستعاه تشكيل ماگماى مادر آن است و از اين رو مىتواند اطلاعات با ارزشى را در مورد خاستخاه زمينساختى ارائه بدهد

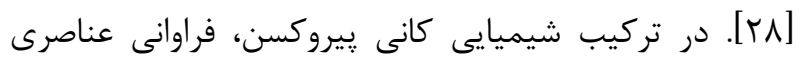

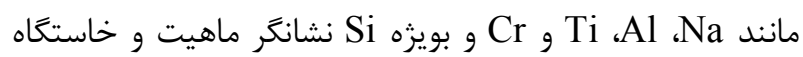

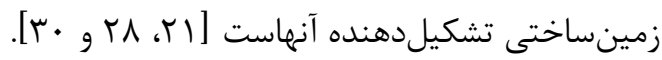

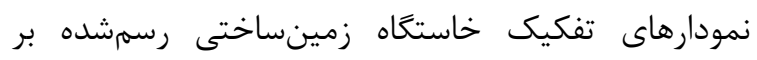

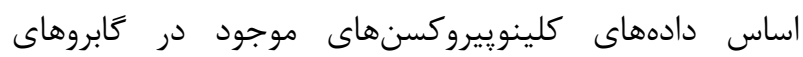
فتحآباد نشان مى دهد كه سنغهاى منطقه مورد بررسى وابسته به مناطق قليايى درون صفحهاى هستند كه در يك خاستخاه زمينساختى نوع كافت درون صفحهاى تزريق شدهاند. نيسبت و ييرس [FF] نمودار دوتايى F1 نسبت به

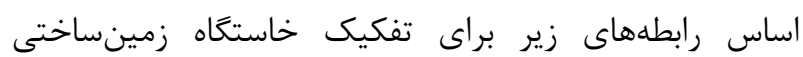
تيرو كسنها ارائه نمودند: $\mathrm{F} 1=-\left(0.012 * \mathrm{SiO}_{2}\right)-\left(0.0807 * \mathrm{TiO}_{2}\right)+(0.0026 *$ $\left.\mathrm{Al}_{2} \mathrm{O}_{3}\right)-(0.0012 * \mathrm{FeO}$ total $)-(0.0026 * \mathrm{MnO})+$ $(0.0087 * \mathrm{MgO})-(0.0128 * \mathrm{CaO})-(0.0419 *$ $\mathrm{Na}_{2} \mathrm{O}$ )

$\mathrm{F} 2=-\left(0.0469 * \mathrm{SiO}_{2}\right)-\left(0.0818 * \mathrm{TiO}_{2}\right)-(0.0212$ $\left.* \mathrm{Al}_{2} \mathrm{O}_{3}\right)-(0.0041 * \mathrm{FeO}$ total $)-(0.1435 * \mathrm{MnO})-$
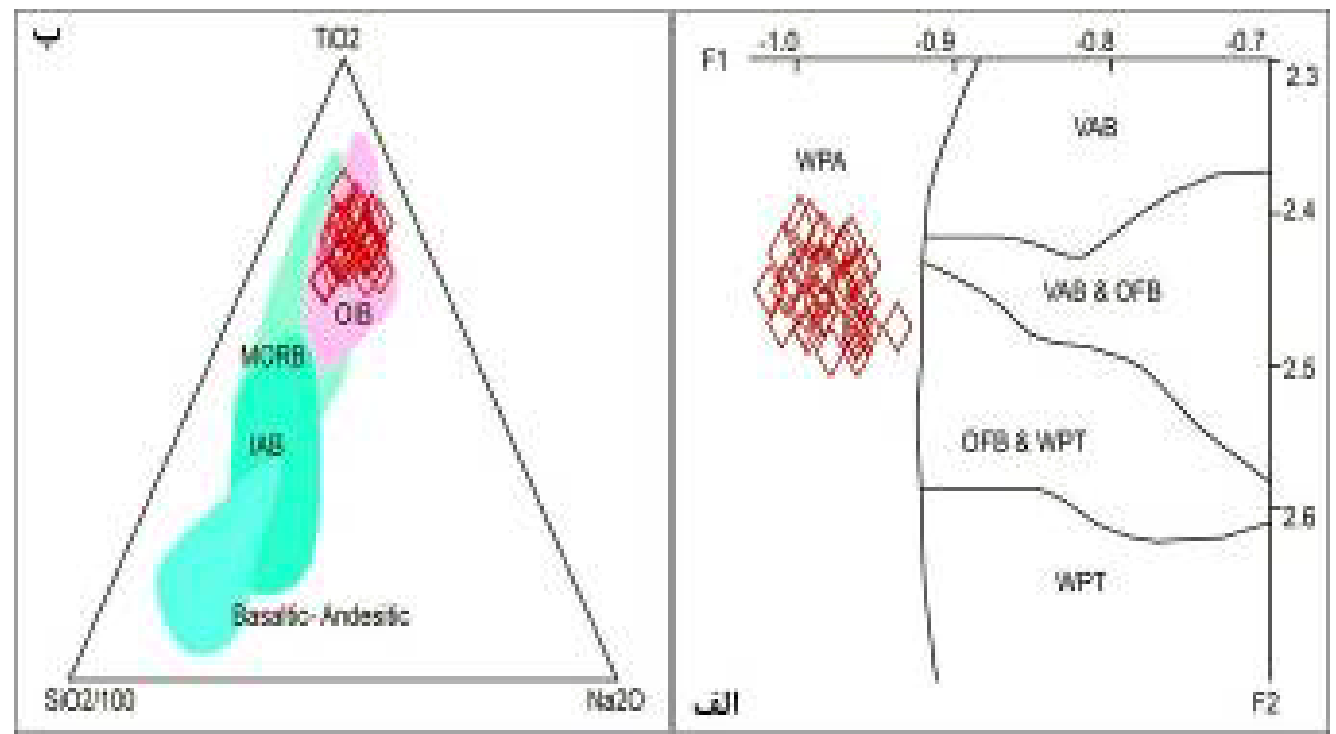

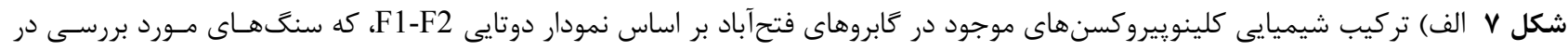

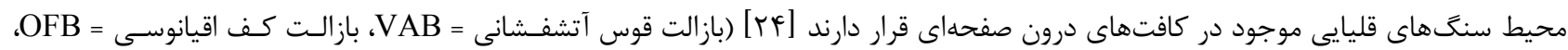

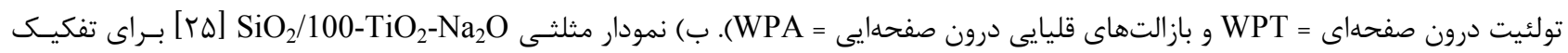

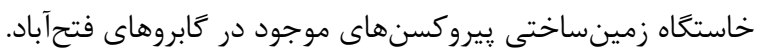




\section{دما و فشارسنجى كلينوييروكسنهاى فتح آباد}

Al

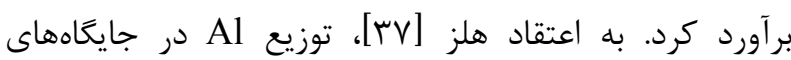
جاروجهى و هشتوجهى كلينوييروكسنها، معيار مناسبى براى

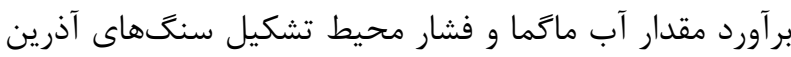
است. بر اين اساس، در نمودار

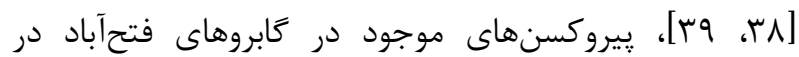
كستره فشارهاى متوسط قرار دارند (شكل 9 الف).

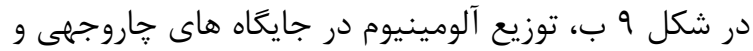

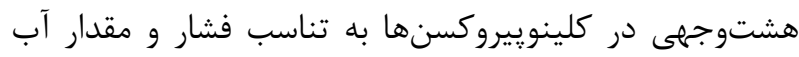

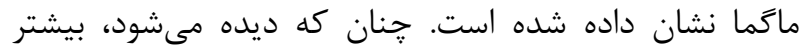

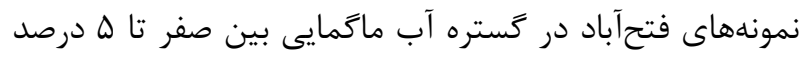

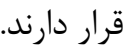

دما و فشارسنجى تشكيل كلينوييروكسنها به روش سوسو [r.]

روش سوسو [F] نيز از روشهايى است كه براى دما-

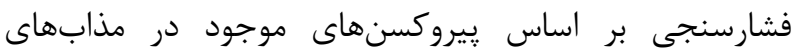

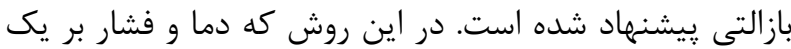

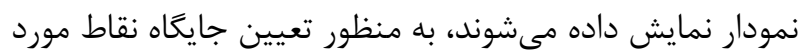

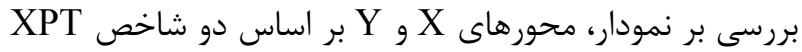

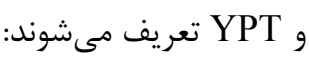
$\mathrm{XPT}=0.446 \mathrm{SiO}_{2}+0.187 \mathrm{TiO}_{2}-0.404 \mathrm{Al}_{2} \mathrm{O}_{3}+$ $0.346 \mathrm{FeO}_{\text {(tot) }}-0.052 \mathrm{MnO}+0.309 \mathrm{MgO}+$ $0.431 \mathrm{CaO}-0.446 \mathrm{Na}_{2} \mathrm{O}$

$\mathrm{YPT}=-0.369 \mathrm{SiO}_{2}+0.535 \mathrm{TiO}_{2}-0.317 \mathrm{Al}_{2} \mathrm{O}_{3}+$ $0.323 \mathrm{FeO}_{\text {(tot) }}+0.235 \mathrm{MnO}-0.516 \mathrm{MgO}-$ $0.167 \mathrm{CaO}-0.153 \mathrm{Na}_{2} \mathrm{O}$

\section{كريزندكى اكسيثن}

يكى از شرايط ترموديناميكى تشكيل سنگَهاى آذرين افزون بر

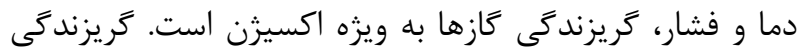
اكسيرن اثر ويزهاى در تغيير دماى ميعان و تركيب مذاب و و بلوري

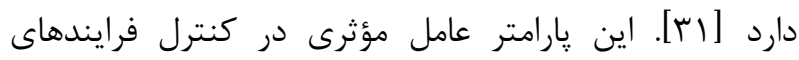

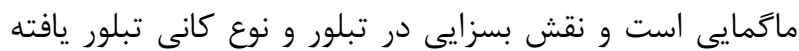

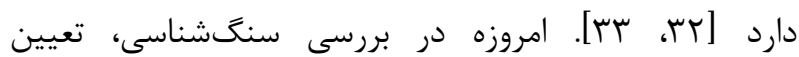
كريزندگى اكسيزن به عنوان اصلىترين فاز كازى درى در كنار

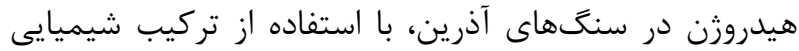

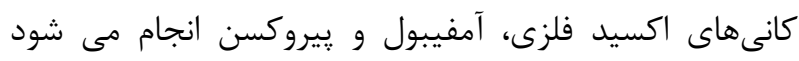

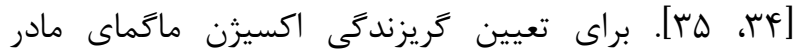
كابروهاى قليايى فتحآباد از نمودار Na+Al Al ${ }^{\mathrm{VI}}+2 \mathrm{mi}+\mathrm{Cr}$

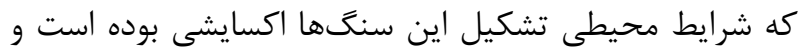

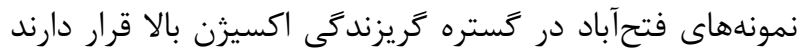

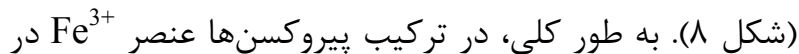

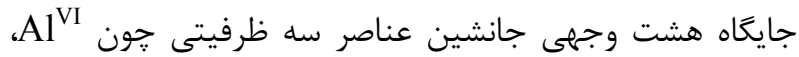

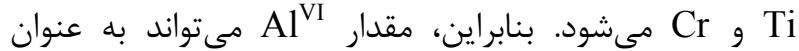

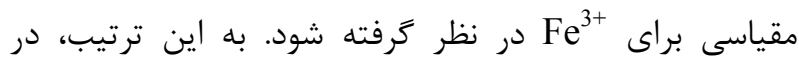
نمودار Na+Al نسبت به Al خط موازنه $\mathrm{Fe}^{3+}=0$

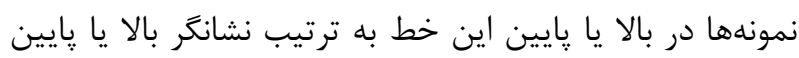

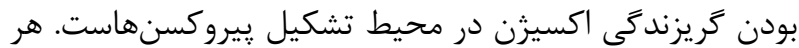
جه فاصله نمونهها از خط كريزندگى اكسيزن در محيط تشكيل آنها بيشتر بوده است

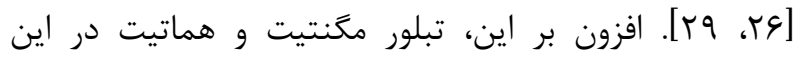
سنگها نيز بيانكر بالا بودن ميزان تريزندگى نبل اكسيرن در محيط تشكيل آنهاست.

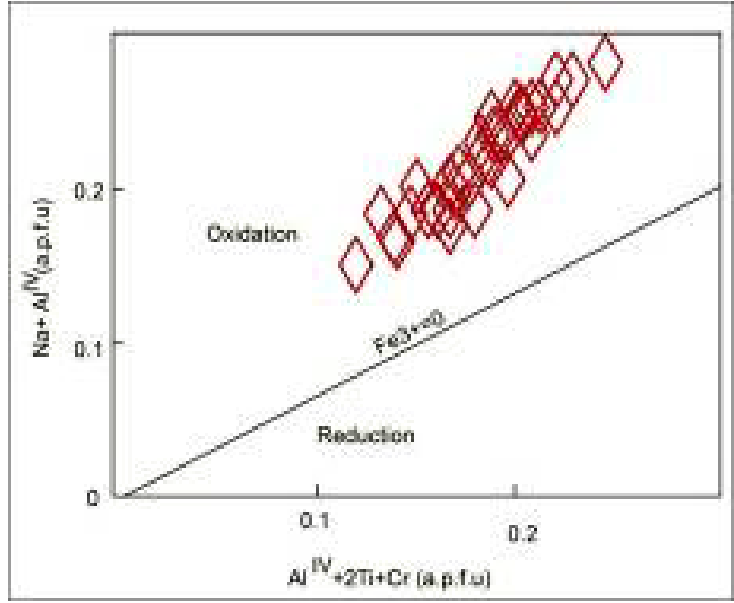

شكل ^ نمودار تغييرات Al نسبت به Na+Al 


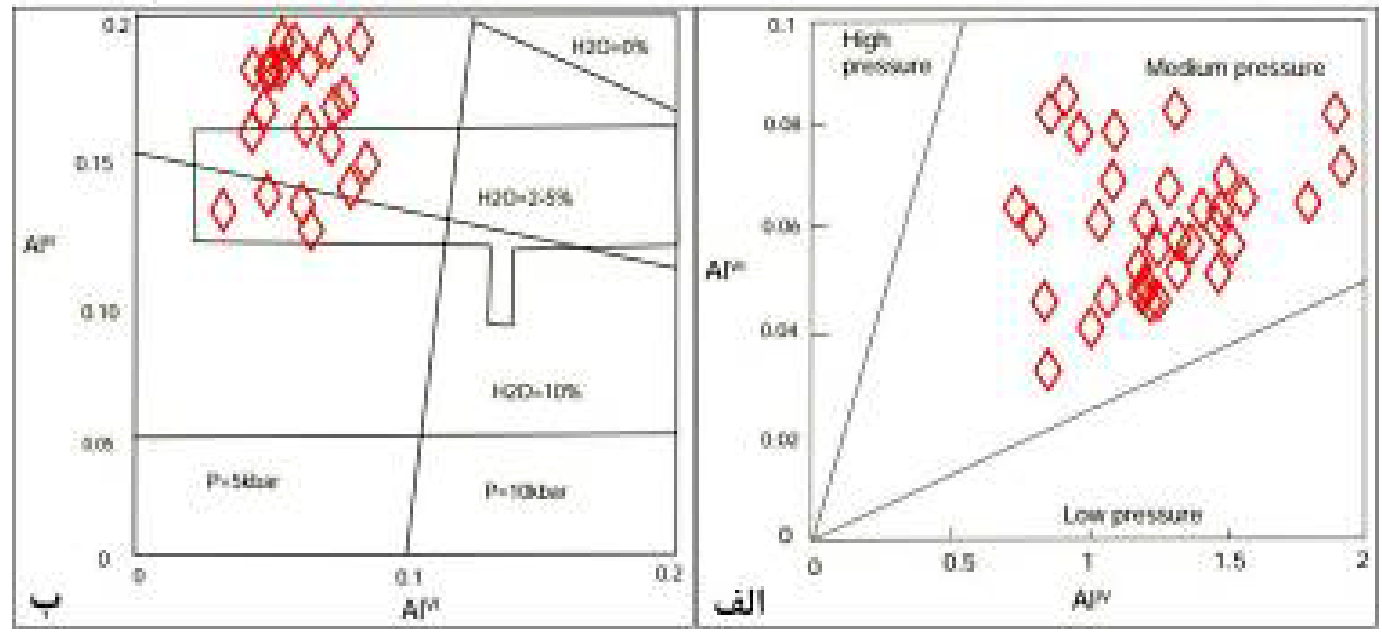

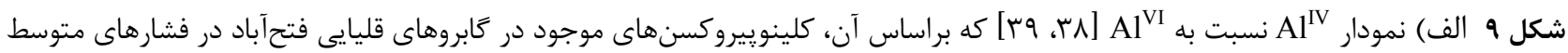

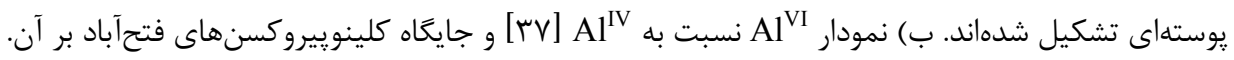

$\mathrm{P}_{(\mathrm{kbar})}=-57.9+0.475 \mathrm{~T}(\mathrm{~K})-40.6(\mathrm{XFeOliq})-$ 47.7(XCaTsCpx $)+0.676\left(\mathrm{H}_{2} \mathrm{Oliq}\right)-153(\mathrm{XCaO}$ $\left.0.5 \mathrm{liqXSiO}_{2} \mathrm{liq}\right)+6.89$ [XAlCpx/XA1O1.5liq] در اين رابطه، براى هر كاتيون Al تعداد \& اتم اكسيرن منظور شده و XAlCpx نيز از رابطه زير قابل محاسبه است: $\mathrm{XAlCpx}=\mathrm{XAl}^{(\mathrm{VI})} \mathrm{Cpx}+\mathrm{XAl}^{(\mathrm{VI})} \mathrm{XPX}(\varphi)$

نتايج دما و فشارسنجى ي يروكسنهاى موجود در كابروهاى قليايى فتحآباد براساس اين رابطه ها در جدول ب ارائه شده دائه

نتايج دما و فشارسنجى كلينوييروكسنهاى موجود در

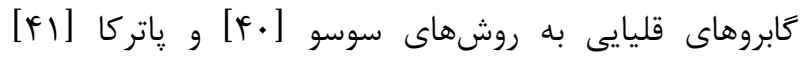

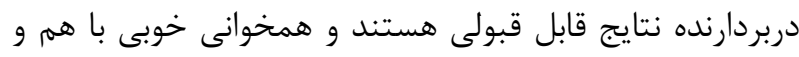

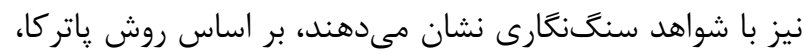

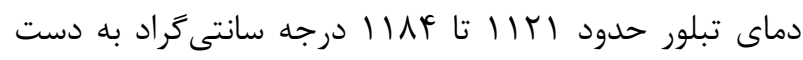
آمده است كه اين گستره دمايى توسط روش ترود ترسيمى سوسو

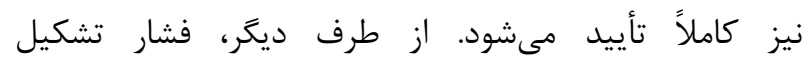

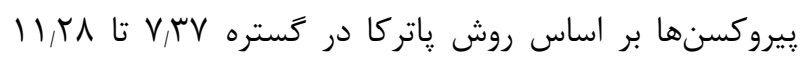

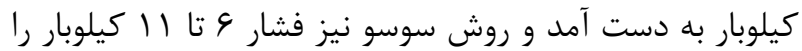

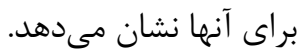

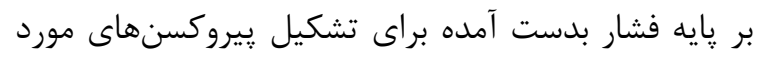

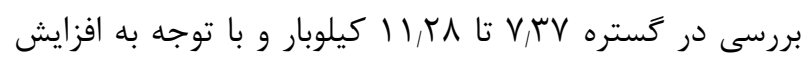

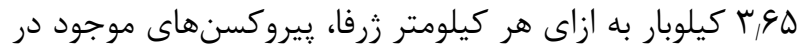

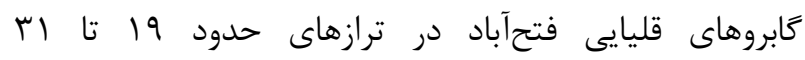

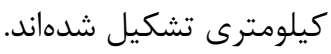

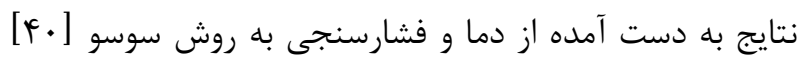

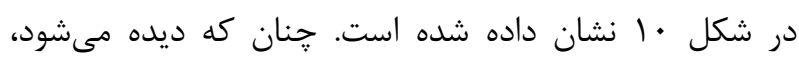

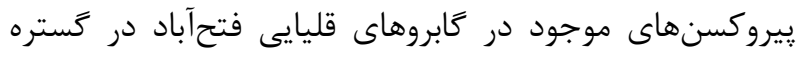

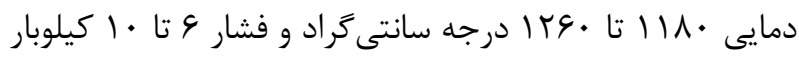

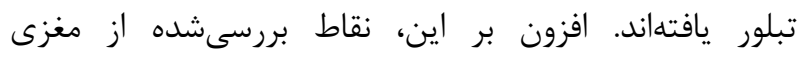

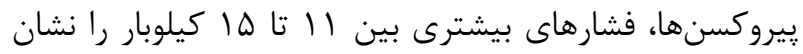

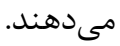

دما و فشارسنجى به روش ياتركا [Fl]

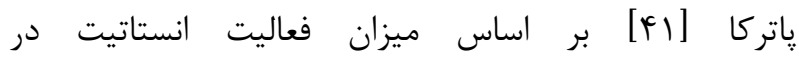
كلينوييروكسن (محاسبه شده توسط نيميس و تيلور [FY] باتئ) روش جديد و بسيار مناسبى را براى تعيين دماى تبلور

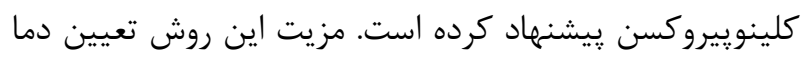

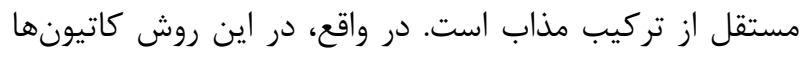

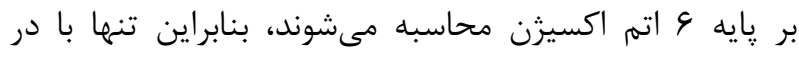

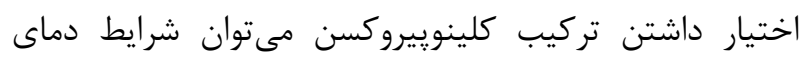

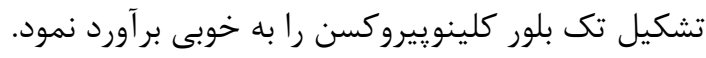

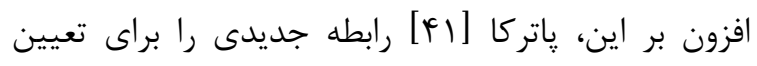

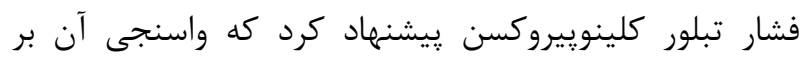

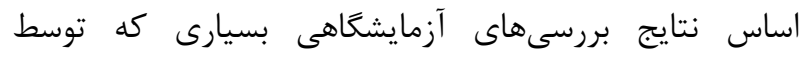

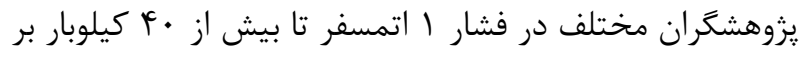

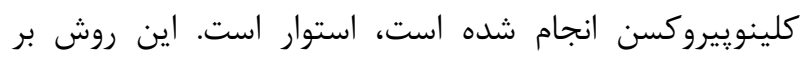

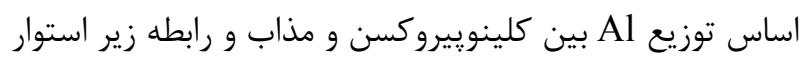




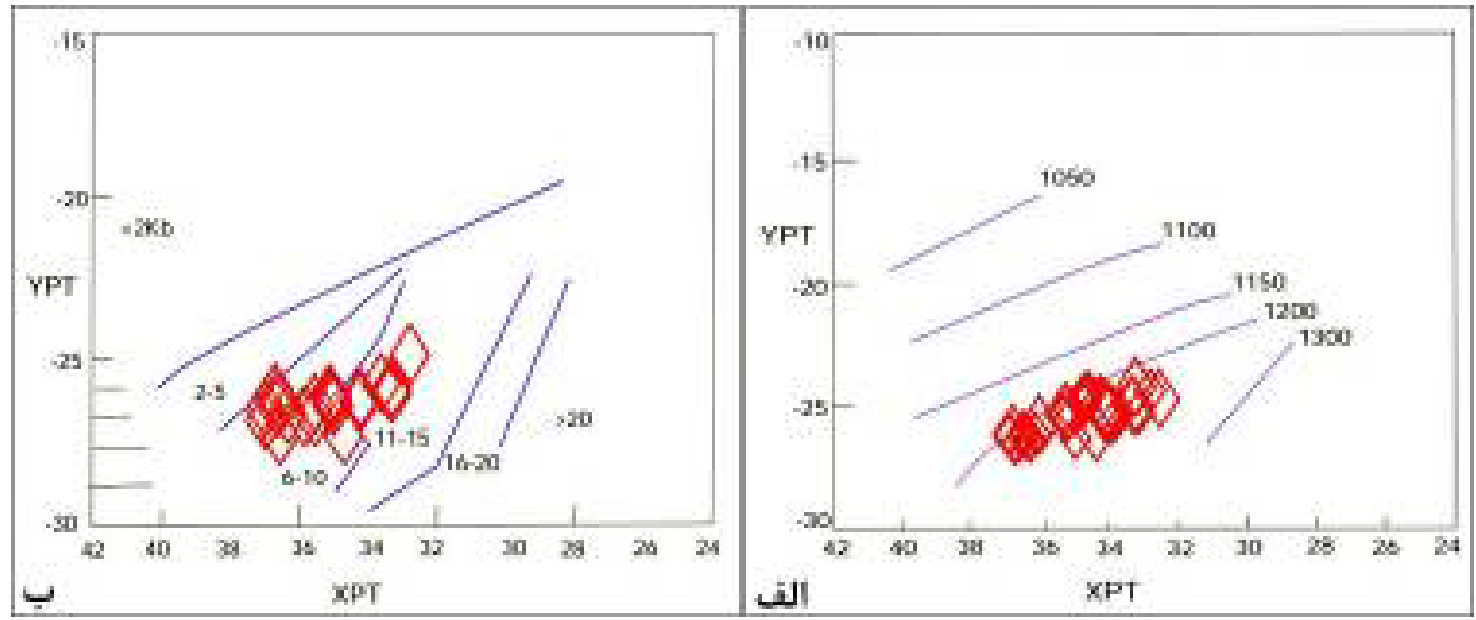

شكل •ا الف) برآورد دما و ب) فشار تشكيل كلينوييروكسنهاى موجود در كابروهاى قليايى فتحآباد با استفاده از روش سوسو [F].

جدول r نتايج دما-فشارسنجى بيروكسنهاى موجود در كابروهاى قليايى فتحآباد به روش باتركا [FY].

\begin{tabular}{|c|c|c|c|c|c|c|c|c|c|c|c|c|}
\hline نمونه & P1 & P2 & P3 & P4 & P5 & P6 & P7 & P8 & P9 & P10 & P11 & P12 \\
\hline $\mathrm{P}(\mathrm{kb})$ & $1, i v$ & $1, r \varphi$ & $11, \cdot$ & $1 \cdot, 9$. & $1 \cdot \gamma \cdot$ & $1 \cdot, r$. & $q, b 1$ & $1 \cdot \gamma \cdot \gamma \cdot$ & $1 \cdot, \mu$. & 9,51 & $11,1$. & $V_{/} \wedge \vee$ \\
\hline $\mathrm{T}^{\circ}(\mathrm{C})$ & 110. & 1148 & $11 \pi 1$ & 119. & $11 V F$ & 1181 & 1191 & $11 \mathrm{Vr}$ & 1199 & $11 \Delta T$ & $11 \mathrm{VF}$ & $11 f \Delta$ \\
\hline نمونه & P13 & P14 & P15 & P16 & P17 & P18 & P19 & P20 & P21 & P22 & P23 & P24 \\
\hline $\mathrm{P}(\mathrm{kb})$ & $\wedge, \wedge \varphi$ & 1.9. & $11, \pi$. & $1, r \mu$ & $q \cdot v$ & $1, \vee 9$ & $1 \cdot 9$. & 11,51 & $१ / \wedge \Delta$ & $q_{l} \cdot v$ & $1, v q$ & 9,10 \\
\hline $\mathrm{T}^{\circ}(\mathrm{C})$ & 1101 & $11 \mathrm{~V}$. & 1114 & $11 F A$ & $110 T$ & $11 F v, r$ & $11 \%$. & llNF & $\||r|$ & $11 \Delta r$ & $11 \mathrm{FV}$ & $11 \Delta \Delta$ \\
\hline نمونه & P25 & P26 & P27 & P28 & P29 & P30 & P31 & P32 & P33 & P34 & P35 & \\
\hline $\mathrm{P}(\mathrm{kb})$ & $V, T V$ & 9,48 & 1,14 & $q_{1},$. & 9,94 & $\Lambda, \Delta\rangle$ & 1,90 & 9,14 & $9 / 10$ & $V, r V$ & 9,49 & \\
\hline $\mathrm{T}^{\circ}(\mathrm{C})$ & $11 r v$ & $\| \Delta \Delta$ & 110. & $11 \Delta T$ & 1195 & 110. & $11 \Delta 9$ & $11 \Delta \Lambda$ & $11 \Delta \Delta$ & $11 \pi \mathrm{V}$ & $11 \Delta \Delta$ & \\
\hline
\end{tabular}

ييروكسنهاى موجود در بازالتهاى قليايى جزاير اقيانوسى

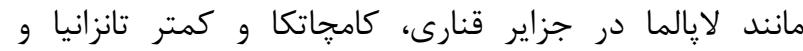

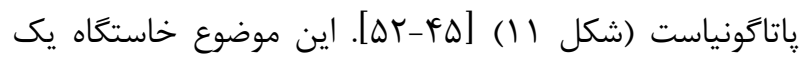

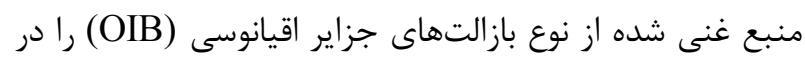

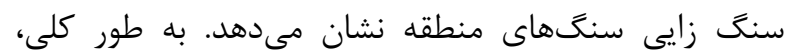

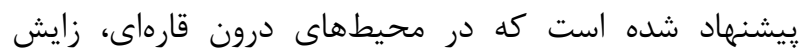

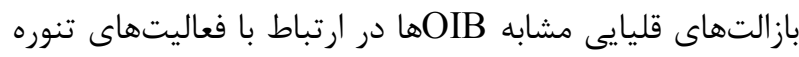

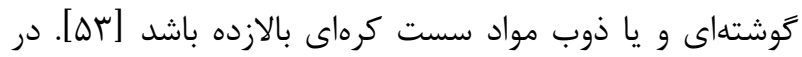

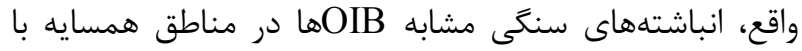

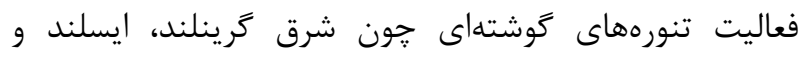

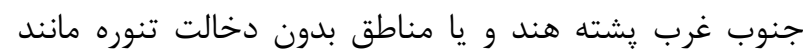

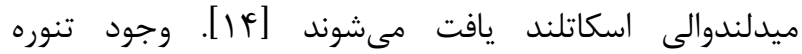

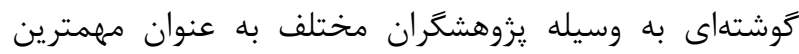

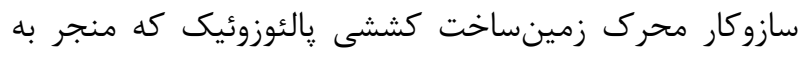
بازشدىى پالئوتتيس در مركز و شرق آسيا شد، بِيشنهاد شده

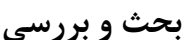
بررسىهاى انجامشده بر شيمى كانى ضيروكسن در كابروهاى

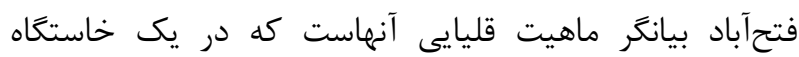

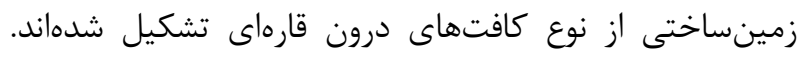

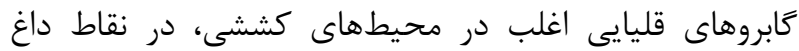

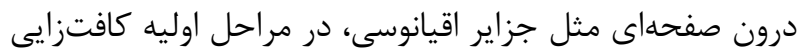

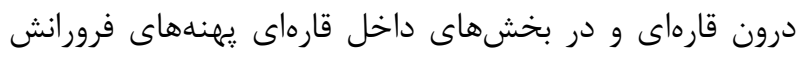

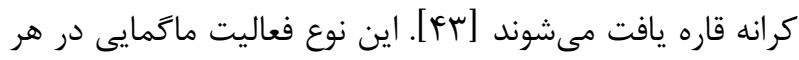
قارهاى اغلب با كشش فعال سنَ كره ایى در مكان كافتهاى

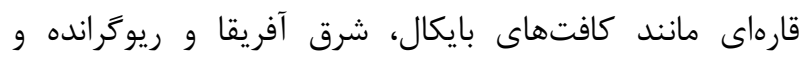

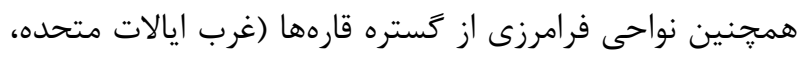
شرق جين، جنوب شرق آسيا و جنوب شرق استراليا) همراه

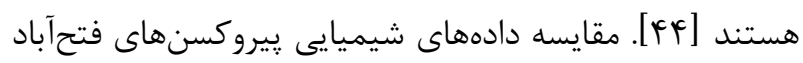
با پيروكسنهاى قليايى مربوط به ساير محيطهاى زمين دانين

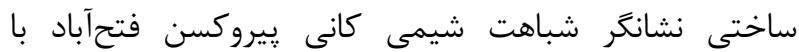


اقيانوسى در شمال ايران (در مشهد، فريمان و دره انجير) و

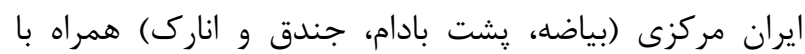
توالى ضخيم ماگمايى سازندهاى سلطان ميدان در كوههاى

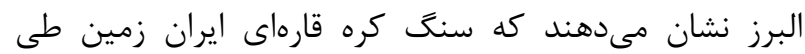
دوران پالئوروئيك يِيشين به واسطه فرايند كافتزايى دهار

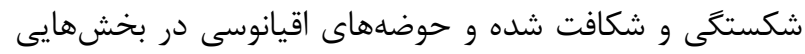
از فلات ايران مانند منطقه شمال (افيوليتهاى مشهد و تالش)

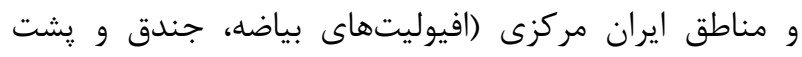

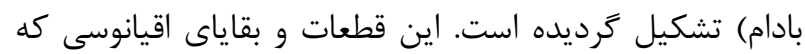

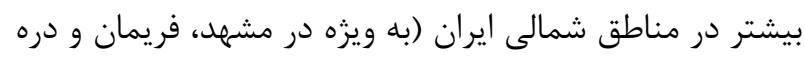
انجير) و ايران مركزى (جندق و انارك) برونزد دارند، بقاياى

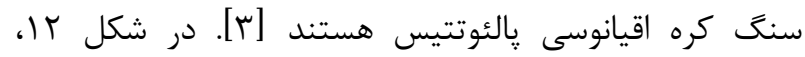

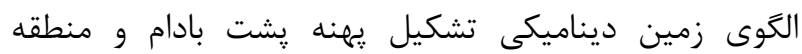

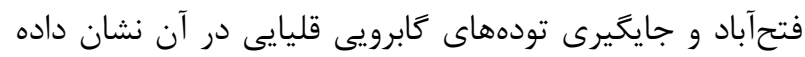

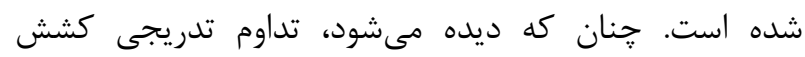
يوستهاى از كامبرين رِين و اردوويسين ريشين سبب خيزش

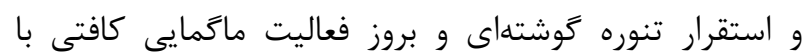
ماهيت قليايى شده است و ديوريت، كابروها و بازالتهاى قليايى منطقه فتحآباد در اين مرحله جايخيرى كردهاند.
است [DF]. افزون بر اين، بررسىهاى ساكانى و همكاران [IF]

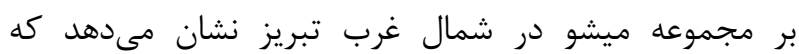

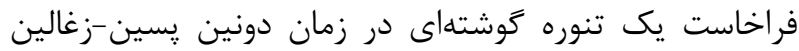

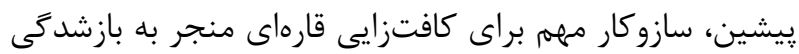

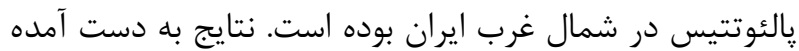

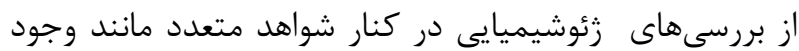
ناييوستخى در قاعده رسوبهاى دوره زغالين (كربونيفر) ايران

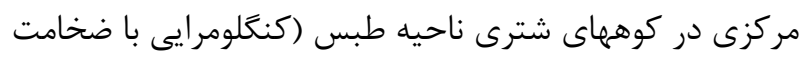
•r متر در قاعده سازند سردر كه با حالت دگرشيب روى سازند

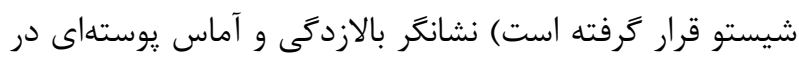

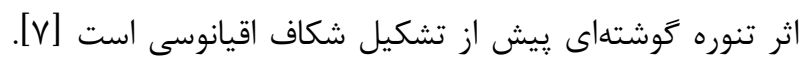

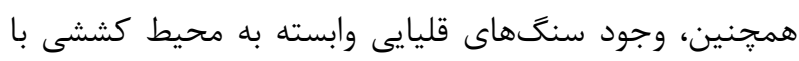
سن اردوويسين، سيلورين و كربونيفر و وجود افيوليتهاى يشت

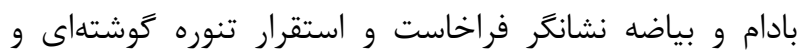
رخداد فرايند كافتزايى و تبديل آن به كافت اقيانوسى طى بـ يالئوزوئيك ييشين در اين منطقه است [هـ]. افزون بر اين،

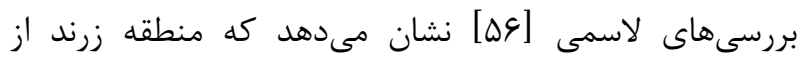

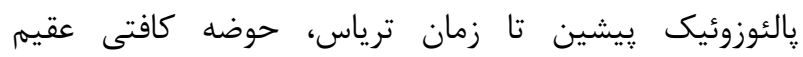

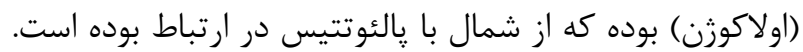
شواهد زمينشناسى متعدد مانند وجود قطعات و بور بقاياى

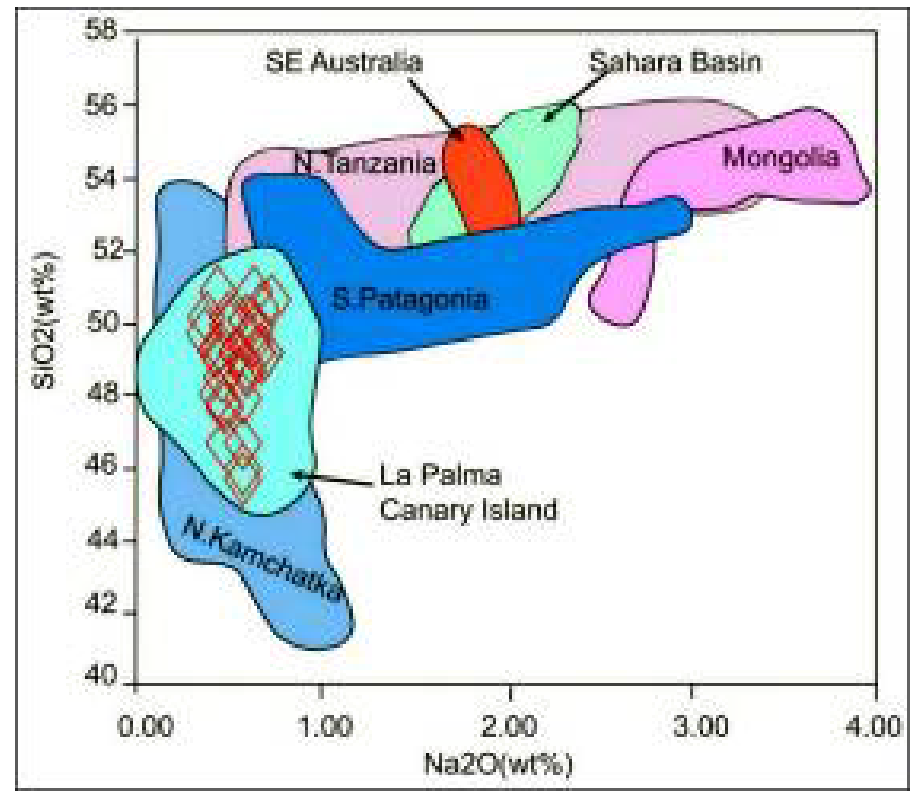

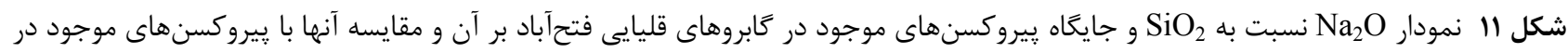

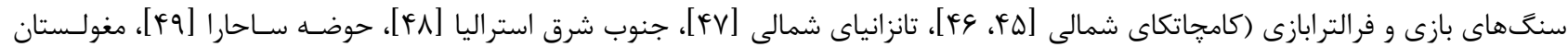

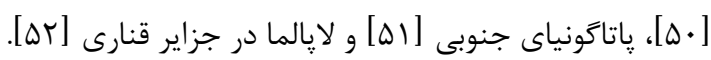




\section{Ordivician to Silurian}

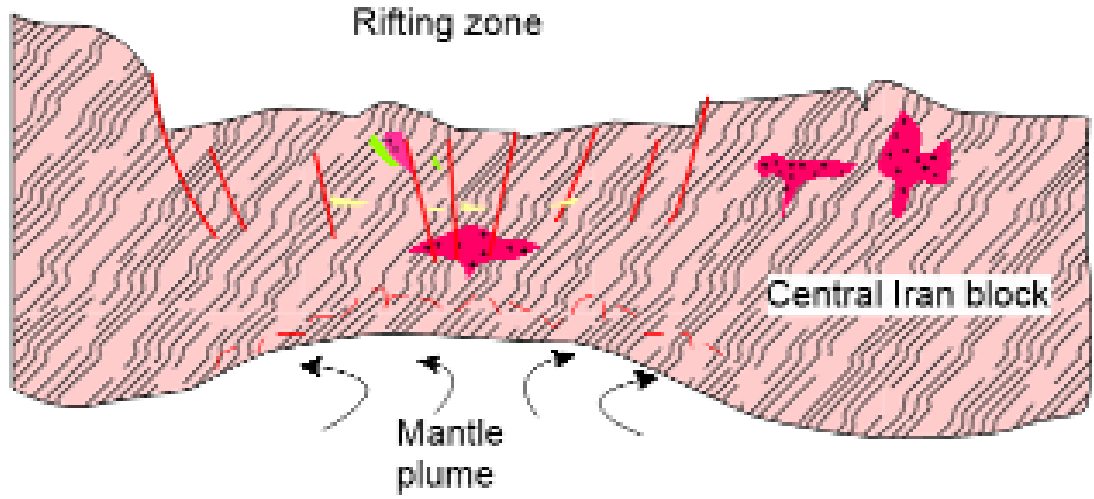

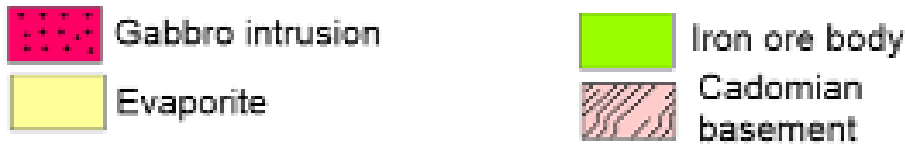

شكل rا الكَوى زمينديناميكى ارائه شده براى كافتزايى در ايران مركزى طى پالئوزوئيك بِيشين (بركرفته از مرجع [هـ]].

فتحآباد با يُروكسنهاى قليايى مربوط به ساير محيطهاى زمين ساختى نشانكر شباهت شيمى كانى پيروكسنهاى منطقائه فتحآباد با بيروكسنهاى موجود در بازالتهاى قليايى جزاير

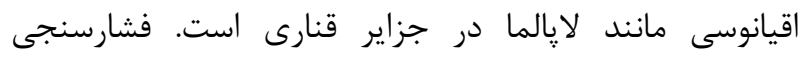

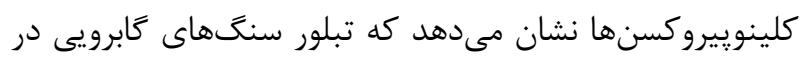

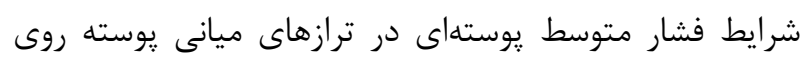
داده است. حجم آب ماكما طى تبلور ماكما بالا بوده است و كابروها در شرايط كريزندگى بالاى اكسيرن شكل كرفتهاند. ماهيت قليايى مشابه جزاير اقيانوسى ديده شده براى كابروهاي

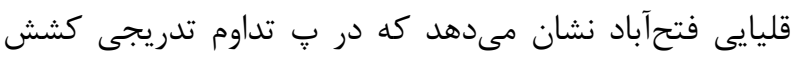

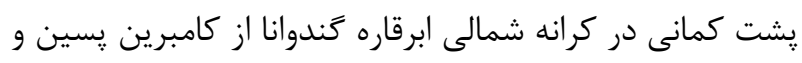

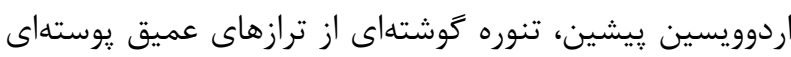

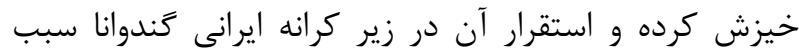
بروز فعاليت ماكمايى كافتى قليايى شده است و دين ديوريت، كابروها و بازالتهاى قليايى منطقه فتحآباد در اين مائ مرحله جايخيرى كردهاند.

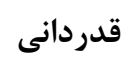

نكارنده از زحمات جناب آقاى يوسف وصالى به سبب هماهنكى در انجام تجزيههاى ريزكاو الكترونى در دانشخاه كانازاواى زاين

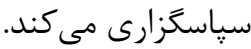

برداشت سنگ ساى كابرويى منطقه فتحآباد بخشى از فعاليت ماتمايى

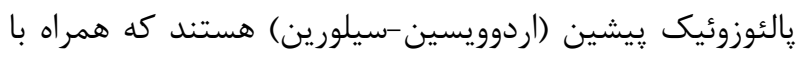
استوكهاى ديوريتى، دايك و سيلهاى ديابازى متعدد

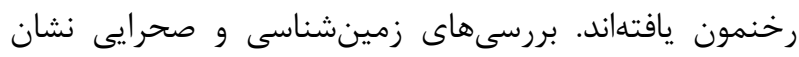
مىدهند كه اين كابروها مهمترين تودههاى نفوذى در منطقه هستند. ويزگى اصلى كابروها وجود بلورهاى آمفيبول قهوهاى

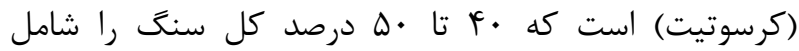

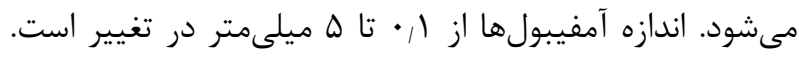

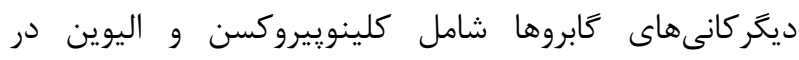

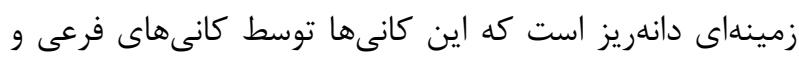

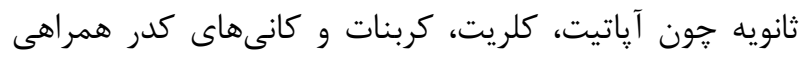
مىشوند. بررسى شيمى كانى پِيروكسن در كابروهاى منطقه

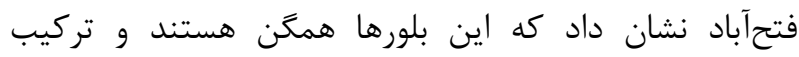

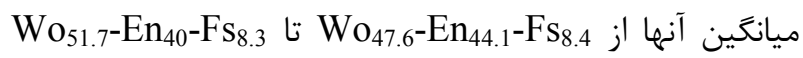
در تغيير است. اين كانىها داراى تركيب ديويسيد بوده و جز إنز سرى قليايى تا برقليايى هستند. بررسى شيمى بيرى بيروكسن

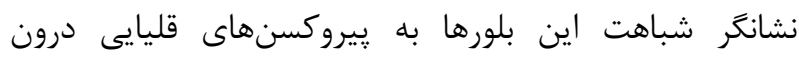
صفحهاى و بازالتهاى جزاير اقيانوسى است. افزون بر اين، مقايسه دادههاى شيميايى پيروكسنهاى موجود در كابروهاى براي 
rocks from the Sarve-Abad ophiolites (Kurdistan region, Iran): Evidence for interaction between MORB-type asthenosphere and OIB-type components in the southern Neo-Tethys Ocean", Tectonophysics 621 (2014) 132-147.

[9] Derakhshi M., Ghasemi H., Sahami T., "Geology and Petrology of the Soltan Maydan Basaltic Complex in North-Northeast of Shahrud, Eastern Alborz, North of Iran (in Persian)", Scientific Quarterly Journal, GEOSCIENCES 23 (2014) 63-76.

[10] Ghasemi H., "Investigation of Upper Precambrian -Lower Paleozoic Magmatism and Metamorphism in N \& SE of Shahrood (Soltan Maidan Basaltic Suite \& Biarjomand Metamorphic and Igneous Complex) (in Persian)", Iran National Science Foundation, Proposal No: 90004893 (2012).

[11] Ghasemi H., Derakhshi M., "Mineralogy, geochemistry and role of olivine mechanical separation in generation of Lower Paleozoic igneous rocks in Shirgesht area, NW of Tabas, Central Iran (in Persian)", Iranian journal of crystallography and mineralogy 16 (2008) 207224.

[12] Ghasemi H., Kazemi Z., "Tectonic setting and source characteristics of the Abarsej Formation igneous rocks (Upper Ordovician), eastern Alborz, north of Shahrood (in Persian)", Iranian journal of crystallography and mineralogy 21 (2013) 319330.

[13] Ghasemi H., Khanalizadeh A., "Toye-Darvar A-type granitoid, southwest of Damghan: Constraints on the Paleotethyan extensional basin of Lower Paleozoic's in Alborz (in Persian)", Iranian journal of crystallography and mineralogy 20 (2013) 3-24.

[14] Saccani E., Azimzadeh Z., Dilek Y., Jahangiri A., "Geochronology and petrology of the Early Carboniferous Misho Mafic Complex (NW Iran), and implications for the melt volution of PaleoTethyan rifting in Western Cimmeria", Lithos 162 163 (2013) 264-278.

\section{مراجع}

[1] Shafaii Moghadam H., Li X.H., Griffin W.L., Stern R.J., Thomsen T.B., Meinhold G., Aharipour R., OReilly S.Y., "Early Paleozoic tectonic reconstruction of Iran: tales from detrital zircon geochronology", Lithos 268-271 (2017) 87-101.

[2] Shafaii Moghadam H., Li X.H., Ling X.X., Stern R.J., Santos J.F., Meinhold G., Ghorbani Gh., Shahabi Sh., "Petrogenesis and tectonic implications of Late Carboniferous A-type granites and gabbronorites in NW Iran: geochronological and geochemical constraints", Lithos 216 (2014) 118-135.

[3] Shafaii Moghadam H., Li X.H., Ling X.X., Stern R.J., Kheder Z.M., Chiaradia M., Ghorbani Gh., Arai Sh., Tamura A., "Devonian to Permian evolution of the Paleo-Tethys Ocean: New evidence from $\mathrm{U}-\mathrm{Pb}$ zircon dating and $\mathrm{Sr}-\mathrm{Nd}-\mathrm{Pb}$ isotopes of the Darrehanjir-Mashhad ophiolites, NE Iran", Gondwana Research 28 (2015) 781-799. [4] Shafaii Moghadam H., Khademi M., Hu Z., Stern R.J., Santos J.F., Wu Y., "Cadomian (Ediacaran-Cambrian) arc magmatism in the Chah Jam-Biarjmand metamorphic complex (Iran): Magmatism along the northern active margin of Gondwana", Gondwana Research 27 (2013) 439-452.

[5] Berberian M., King G.C.P., "Towards a paleogeography and tectonic evolution of Iran", Canadian Journal of Earth Sciences 18 (1981) 210-265.

[6] Hassanzadeh J., Stockli D.F., Horton B.K., Axen G.J., Stockli L.D., Grove M., Schmitt A.K., Walker J.D., " $\mathrm{U}-\mathrm{Pb}$ zircon geochronology of late Neoproterozoic-Early Cambrian granitoids in Iran: implications for paleogeography, magmatism, and exhumation history of Iranian basement", Tectonophysics 451 (2008) 71-96.

[7] Stampfli G.M., "Etude geologique generale de $l$ Elbourz oriental au $S$ de Gonbad-e-Qabus, Iran $N$-E", Ph.D. thesis, Universite de Geneve, Geneve, Switzerland (1978) $329 \mathrm{p}$.

[8] Saccani E., Allahyari Kh., Rahimzadeh B., "Petrology and geochemistry of mafic magmatic 
basalts as petrogenetic indicator", Chemical Geology 77 (1989) 165-182.

[26] Sakhaee Z., Davoudian Dehkordi A., Shabanian N., Paydary M., "Approach on the characteristics of basic magma rocks sarkoobeh (north Khomein) by clinopyroxene mineral chemistry (in Persian)", Iranian journal of crystallography and mineralogy 23 (2015) 533544.

[27] Pyghambary S., "Tectonomagmatic characteristics of ophiolitic gabbroids from south Orzuieh (south of Baft, Kerman) ophiolite complex: insights from clinopyroxene chemistry (in Persian)", Iranian journal of crystallography and mineralogy 26 (2018) 301-314.

[28] Le Bas M.J., "The role of aluminium in igneous clinopyroxenes with relation to their parentage", American Journal of Science 260 (1962) 267-288.

[29] Keshtkar E., Ghorbani M., "Study of clinopyroxenes in the intrusions of Karaj-Taleghan Axis (in Persian)", Iranian journal of crystallography and mineralogy 24 (2016) 405416.

[30] Sun C.M., Bertrand J., "Geochemistry of clinopyroxenes in plutonic and volcanic sequences from the Yanbian Proterozoic ophiolites (Sichuan Province, China) Petrogenetic and geotectonic implications", Schweizerische Mineralogische und Petrographische Mitteilungen 71 (1991) 243- 59.

[31] France L., Koepke J., Ildefonse B., Cichy S.B., Deschamps F., "Hydrous partial melting in the sheeted dike complex at fast spreading ridges: experimental and natural observations", Contributions to Mineralogy and Petrology 160 165 (2010) 683-704.

[32] Kilinc A., Carmichael I.S.E., Rivers M.L., Sack R.O., "The ferric-ferrous ratio of natural silicate liquids equilibrated in air", Contributions to Mineralogy and Petrology 83 (1983) 136-140.

[33] Botcharnikov R.E., Koepke J., Holtz F., McCammon C., Wilke M., "The effect of water activity on the oxidation and structural state of Fe
[15] Alavi M., "Tectonic map of the Middle East", Scale 1:5,000,000, Geologic Survey of Iran (1991). [16] Berberian M., "Active faulting and tectonics of Iran", In: Gupta H.K., Delany F.M. (Editors), Zagros-Hindu Kush Himalaya Geodynamic Evolution. American Geophysical Union Geodynamic Series, Washington, D.C. (1981) 3369.

[17] Vahdati Daneshmand F., "Geological Map of Davaran", Scale 1:100,000, Sheet 7251, Geological Survey of Iran (1995).

[18] Gill R., "Igneous Rocks and Processes: A Practical Guide", Wiley-Blackwell (2010) 438 p.

[19] Whitney D.L., Evans B.W., "Abbreviations for names of rock-forming minerals", American Mineralogist 95 (2010) 185-187.

[20] Droop G.T.R., "A general equation for estimating $\mathrm{Fe}^{3+}$ concentrations in ferromagnesian silicates and oxides from microprobe analyses, using stoichiometric criteria", Mineralogical Magazine 51 (1987) 431-435.

[21] Leterrier J., Maury R.C., Thonon P., Girard D., Marchal M., "Clinopyroxene composition as a method of identification of the magmatic affinities of Paleo-volcano series", Earth and Planetary Science Letters 59 (1982) 139-154.

[22] Morimoto N., Fabries J., Ferguson A.K., Ginzburg I.V., Ross M., Seifert F.A., Zussman J., Aoki K., Gottardi G., "Nomenculature of pyroxenes", American Mineralogist 73 (1988) 1123-1133.

[23] D'Antonio M., Kristensen M.B., "data report: electron microprobe investigation of primary minerals of basalts from the west Philippine sea basin (Ocean Drilling program Leg 195, site 1201)", In: Shinohara M., Salisbury M.H., Richter C. (Editors), ODP Proceedings Scientific Results 195 (2005) 1-24.

[24] Nisbet E.G., Pearce J.A., "Clinopyroxene composition in mafic lavas from different tectonic setting", Contributions to Mineralogy and Petrology 63 (1977) 149-160.

[25] Beccaluva L., Macciotta G., Piccardo G.B., Zeda O., "Clinopyroxene compositions of ophiolite 
[43] Wilson M., "Igneous Petrogenesis a global tectonic approach", Unwin Hyman, London (1989) $466 \mathrm{p}$.

[44] Sen G., "Petrology: Principles and Practice", Springer, Verlag Berlin Heidelberg (2014) 368 p.

[45] Kepezhinzkas P.K., Defant M.J., Drummond M.S., "Na metasomatism in the island arc mantle by slab melt-peridotite interaction: evidence from mantle xenoliths in the North Kamchatka arc", Journal of Petrology 36 (1995) 1250-1267.

[46] Kepezhinzkas P.K., Defant M.J., Drummond M.S., "Progressive enrichment of island arc mantle by melt-peridotite interaction inferred from Kamchatka xenoliths", Geochimica et Cosmochimica Acta 60 (1996) 1217-1229.

[47] Rudnick R.L., McDonough W.F., Chappel B.W., "Carbonatite metasomatism in the northern Tanzanian mantle: petrographical and geochemical characteristics", Earth and Planetary Science Letters 114 (1993) 463-475.

[48] Yaxley G.M., Crawford A.J., Green D.H., "Evidence for carbonatite metasomatism in spinel peridotite xenoliths from western Victoria, Australia", Earth and Planetary Science Letters 107 (1991) 305-317.

[49] Dautria J.M., Dupuy C., Takheist D., Dostal J., "Carbonate metasomatism in the lithospheric mantle: peridotitic xenoliths from a melititic district of the Sahara basin", Contributions to Mineralogy and Petrology 111 (1992) 37-52.

[50] Ionov D.A., "Trace element composition of mantle-derived carbonates and coexisting phases in peridotite xenoliths from alkali basalts", Journal of Petrology 39 (1998) 1931-1941.

[51] Gorring M.L., Kay S.M., "Carbonanite metasomatized peridotite xenoliths from southern Patagonia: implications for lithospheric processes and Neogene plateau magmatism", Contributions to Mineralogy and Petrology 140 (2000) 55-72.

[52] Neumann E.R., Sorensen V.B., Simonsen S.L., Johnsen K., "Gabbroic xenoliths from $\mathrm{La}$ Palma, Tenerife and Lanzarote, Canary Islands: evidence for reactions between mafic alkaline Canary Islands melts and old oceanic crust", in a ferro-basaltic melt", Geochimica et Cosmochimica Acta 69 (2005) 5071-5085.

[34] Carmichael I.S.E., "The redox state of basic and silicic magmas: a reflection of their source regions?" Contributions to Mineralogy and Petrology 106 (1991) 129-141.

[35] Behrens H., Gaillard F., "Geochemical aspects of melts: Volatiles and redox behavior", In: Behrens H., Roux J., Neuville D., Siemann M. (Editors), Quantification of dissolved $\mathrm{H}_{2} \mathrm{O}$ in silicate glasses using confocal microRaman spectroscopy, Chemical Geology 229 (2006) 96112.

[36] Schweitzer E.L., Papike J.J., Bence A.E., "Statistical analysis of clinopyroxenes from deepsea basalts", American Mineralogist 64 (1979) 501-513.

[37] Helz R.T., "Phase reactions of basalts in their melting renge at $\mathrm{PH}_{2} \mathrm{O}=5 \mathrm{~Kb}$. Part II Melts composition", Journal of Petrology 17 (1973) 139193.

[38] Aoki K.I., Kushiro I., "Some clinopyroxenes from ultramafc inclusions in Dreiser Weiher, Eifel", Contributions to Mineralogy and Petrology 18 (1968) 326-337.

[39] Aoki K.I., Shiba I., "Pyroxenes from lherzolite inclusions of Itinom e-Gata, Japan", Lithos 6 (1973) 41-51.

[40] Soesoo A., "A multivariate statistical analysis of clinopyroxene composition: empirical coordinates for the crystallisation PT-estimations", Geological Society of Sweden - Geologiska föreningen 119 (1997) 55-60.

[41] Putirka K.D., "Thermometers and Barometers for Volcanic Systems", Reviews in Mineralogy and Geochemistry 69 (2008) 61-120.

[42] Nimis P., Taylor W.R., "Single Clinopyroxene Thermobarometery for Garnet Peridotites. Part I. Calibration and Testing of the Cr-in-Cpx Barometer and an Enstitite-in-Cpx Thermometer", Contributions to Mineralogy and Petrology 139 (2000) 541-554. 
[55] Vesali Y., Esmaeili D., Sepidbar F., Shaebi M., Niromand Sh., "Petrology, geochemistry and tectonic setting of alkaline mafic rocks in the Jalal Abad area in the $N W$ of Zarand (Kerman Province): Evidence for Paleo-Tethys rifting in the Central Iran (in Persian)", Journal of Petrology 9 (2018) 1-20.

[56] Lasemi Y., "Depositional environments of the Ordovician rocks of Iran (syn-rift sequence) and formation of the Paleotethys passive margin (in Persian)", Proceedings of the 17th annual meeting of the Geological Survey of Iran, Tehran, Iran (1999).
Journal of Volcanology and Geothermal Research 103 (2000) 313-342.

[53] McKenzie D.P., O’Nions R.K., "Partial melt distribution from inversion of rare earth element concentration", Journal of Petrology 32 (1991) 1021-1091.

[54] Dai J., Wang C., Hébert R., Li Y., Zhong H., Guillaume R., Bezard R., Wei Y., "Late Devonian OIB alkaline gabbro in the Yarlung Zangbo Suture Zone: Remnants of the Paleo-Tethys?", Gondwana Research 19 ( 2011) 232-243. 